NBER WORKING PAPER SERIES

\title{
ESTIMATING THE WELFARE EFFECTS OF DIGITAL INFRASTRUCTURE
}

\author{
Shane M. Greenstein \\ Pablo T. Spiller
}

Working Paper 5770

\section{NATIONAL BUREAU OF ECONOMIC RESEARCH 1050 Massachusetts Avenue \\ Cambridge, MA 02138 \\ September 1996}

We would like to thank Tim Bresnahan, Ariel Pakes, Mike Riordan and seminar participants at the Telecommunications Policy Research Conference, University of Illinois, NBER IO and NBER Productivity workshops, Rutgers University and Northwestern University for their comments and suggestions. Greenstein thanks the hospitality of the Institute for Management, Innovation and Organizations at the Haas School of Business, UC Berkeley, where he visited when this project began. Patrick Moreton and Susan McMaster provided research assistance at different stages in this project. The Ameritech Telecommunications Program at the University of California, Berkeley, the Institute for Government and Public Affairs at the University of Illinois, and the National Science Foundation provided financial support. This paper is part of NBER's research program in Productivity. Any opinions expressed are those of the authors and not those of the National Bureau of Economic Research.

(C) 1996 by Shane M. Greenstein and Pablo T. Spiller. All rights reserved. Short sections of text, not to exceed two paragraphs, may be quoted without explicit permission provided that full credit, including (C) notice, is given to the source. 


\title{
ESTIMATING THE WELFARE EFFECTS \\ OF DIGITAL INFRASTRUCTURE
}

\begin{abstract}
While much economic policy presumes that more information infrastructure yields higher economic returns, little empirical work measures the magnitudes of these returns. We examine investment by local exchange telephone companies in fiber optic cable, ISDN lines and signal seven software, infrastructure which plays an essential role in bringing digital technology to local telephone networks. We estimate the elasticity of the derived demand for infrastructure investment faced by local exchange companies, controlling for factors such as local economic activity and the political disposition of state regulators. Our model postulates a regulated profit maximizing local exchange firm and a regulatory agency with predetermined political leanings in favor of consumer prices or firm profits. The model accounts for variation in state regulation and local economic conditions.

In all our estimates we find that consumer demand is sensitive to investment in modern infrastructure, particularly as represented by fiber optic cable. Our estimates imply that infrastructure investment is responsible for a substantial fraction of the recent growth in consumer surplus and business revenue in local telecommunication services.

Shane M. Greenstein

Department of Economics

University of Illinois, Urbana/Champaign

1206 South Sixth Street

Champaign, IL 61820

and NBER

grnstn@uiuc.edu

Pablo T. Spiller

Haas School of Business

University of California, Berkeley

Berkeley, CA 94720

spiller@haas.berkeley.edu
\end{abstract}




\section{Introduction}

Much recent policy discussion presumes that improvements in information infrastructure lead to large economic returns. Despite the explosive growth in recent commentary about the development and impact of digital infrastructure, there have been few attempts to estimate the magnitudes of the economic gains associated with improving information infrastructure.

This should not be a surprise. Some well known problems in the economics of technology, infrastructure and measurement make this estimation particularly difficult. First, calculating the economic trade-off between old and new technologies or equipment requires knowledge about the benefits associated with modern facilities relative to those arising from existing ones. Yet, it is difficult to measure levels of quality and quantity of infrastructure, let alone differences between old and new. Second, although infrastructure improvements may reduce the costs of providing new services and increase the quality of old services, the exact benefits associated with these changes may be difficult to trace. Third, questions about economic benefits require information about the demand for the incremental improvements associated with modernization. Measuring demand for such change requires information about users' valuation, which are also hard to learn. Inferences from actual behavior require appropriate models and extensive data collection. These are not easy to match to each other as the particularities of institutions and markets influence both the availability of data and the appropriateness of the models at hand. Finally, multiple information technology markets comprise the information infrastructure, but at best, any study can only focus on a few markets at a time.

In this study we focus on one type of modem infrastructure, digital technology, in a particularly important setting, local telephone service. We measure how investments in digital technology influence the demand for -- and economic value of -- local telecommunications services. Local telephone networks are a crucial part of the much-anticipated "information super-highway." The main providers of local telephone service in the United States generate revenues in excess of seventy billion dollars in 1992 and they offer service to over ninety percent of the US population. Yet, the benefits associated with modernizing these firm's networks remains sketchy.

More specifically, this study focuses on measuring the impact of modemizing Local 
Exchange Companies' (LECs) telecommunications infrastructure at the sub-state level, which is the most disaggregate level at which one can measure local phone company infrastructure. At this level of aggregation there is a statistical "natural experiment," i.e., there is a large regional variation in the quality of local telephone networks across the United States, particularly in the level of digital technology. Further, LECs also cover different geographic territory, face different state regulatory environments, and operate under very different local economic conditions. Some of these features vary widely across the US and a few vary widely over time. All this regional variation provides an opportunity to relate regional variation in infrastructure quality to regional variation in telephone demand and revenue. While this variation has been recognized for some years as a source of many mini-experiments in telecommunications across the US, it has been difficult to translate into a measurement framework. In this study we offer both a novel data collection effort and a novel modeling framework for taking advantage of this variation.

Several key factors shape our econometric and measurement strategy. First, we need a model of demand that is consistent with economic theory, flexible enough to lend itself to estimation and related welfare inferences, but robust to a variety of specifications. Our "strategy is to treat the demand for infrastructure as a derived demand for the input of a regulated firm, where that input influences the revenues a firm collects. Second, some part of investment behavior responds to factors such as local economic activity and the political disposition of state regulators. We need to control for these factors, so we collect very extensive data on the economic and demographic factors that influence telephone demand. Third, we cannot observe prices, nor the regulated process that determines them, though we can proxy for both. Thus, our goal is to estimate the elasticity of final user demand for infrastructure investment by their LEC, but not employ a method that depends on any particular estimate of the price elasticity of demand.

Our approach attempts to hold measurement problems to the lowest minimum possible, since geographic variation in the quality of local telephone networks should lead to related (and localized) geographic variation in the quality and amount of local telephone revenue. This study also differs from previous research in our econometrics treatment of these issues: we treat modern infrastructure as endogenous, we estimate all effects within the structure of a 
regulator/utility interaction model, and we offer an expanded list of "controls" (i.e., regressors) for related economic behavior. Thus, our study advances novel approaches to issues pertinent to the economics of information infrastructure, empirical models of regulation and the measurement of benefits to users from technical change.

We specifically examine investment in fiber optic cable, Integrated Services Digital Network (ISDN) lines and signal seven software (SS7), infrastructure which plays an essential role in bringing digital technology to LEC's networks (more on the technology below). We broadly interpret these as measures of a whole range of digital technology which are demand enhancing. We find that fiber-optic cable greatly enhances LEC demand, but the contribution from ISDN and SS7 is probably smaller as of 1992, when our data ends. The estimated elasticity of consumer surplus to fiber optic deployment is never less than 7 percent and is much higher in some estimates. The elasticity of consumer surplus for ISDN ranges between zero and 16 percent. The elasticity for SS7 is not robustly estimated.

We cannot say how much of the additional revenue brought about by these investments were or were not captured by the LEC or consumers, but these estimates are consistent with large social returns to investment in digital technology, especially those technologies related to fiber optic cable. Our estimates also appear consistent with industry consensus that in the absence of LEC investment in new technologies, revenues would have fallen in many localities. It is also consistent with the view that LECs differed tremendously in the returns and installation costs associated with these investments due to local economic conditions, and that these differences have narrowed somewhat over time. We also find quantitative evidence that the political and regulatory environment had a large role in shaping the differences in returns to new infrastructure across localities.

\section{The Economic Consequences from Modernizing Infrastructure}

In this study, we ask whether variation in the degree of modernization across regions of the US influences economic outcomes in those regions. What are the additional cost and benefits of upgrading from a merely functional system to a state-of-the-art digital system capable of carrying many additional services? There has been surprisingly little research done on this 
question, though related issues in telecommunications and infrastructure have received considerable attention outside the US context. ${ }^{1,2}$

Our approach to this question is in the spirit of a line of new research primarily on information technology -- and new goods more generally (Bresnahan and Gordon [1996]). ${ }^{\text {TT This }}$ research tries to measure the benefits to users from improvements in technology by estimating the underlying (derived) demand for the new technology or the new service it enables. This literature places emphasis on modeling heterogeneous consumer demand for technical improvement. It tries to link estimation and inferences to the underlying utility associated with new technology, though no standard technique has yet emerged for making such estimates.

Our goals also relate to an extensive literature on the economic consequences of infrastructure investment in modem market economies, where infrastructure is broadly defined as highways, water and sewer systems, schools, hospitals, electrical and transportation facilities, and other publicly owned equipment and structures. ${ }^{+}$We will not review all these studies here, and instead, will focus only on recent studies of the modernization of telecommunications networks in developed economies, a topic relates most closely to our focus. These studies find that a large fraction of economic growth may be attributable to increases in the efficiency of telecommunications infrastructure. ${ }^{5}$ These studies also argue that some part of regional variation in economic activity may be attributed to the quality of regional telecommunications infrastructure. $^{6}$

We are sensitive to many of the methodological concerns raised in these studies. We adopt a framework that has elements of change embedded in it, albeit in a simple structural model. Second, our econometrics framework controls for statistical endogeneity. Third, we use a very disaggregated analysis, below the state level, but contrast infrastructure across many different regions, taking advantage of the statistical variation embedded in cross-regional differences in telecommunications network quality. Fourth, unlike previous studies, our estimation begins to account for some of the institutional features of telecommunications politics and regulatory environment. Fifth, we use a structural model to link our estimates directly back to parameters of direct economic interest, the benefits to buyers from technical change. 


\section{Model and Econometrics}

We undertake our analysis at the level of the local exchange company at the sub-state level. This is the most disaggregate level of data available on local telephone infrastructure. This also takes advantage of the peculiar federalism of local telephone service within the US. Furthermore, every state divides its territory between a regional bell operating company and potentially other local telephone companies, such as GTE or other independents. Thus, two different LECs may face different regional demand and regulatory restrictions even if they are within the same state or within proximate geographic regions.

We observe some of the differences in the quality and quantity of infrastructure between LECs and match it to LEC specific revenue. We also observe some of the variation in local demographic and economic conditions (at the LEC level), as well as some of the differences in state regulatory environments between states. However, we are not able to observe the multiple tariffs that prevail within each LEC for calls of different distance at different times of the day, nor the various toll prices for within-state calls. Thus, to make use of LEC-specific data on revenue and infrastructure, we require a method for estimating an infrastructure elasticity that should not depend on observing prices at all.

\section{Model of demand.}

We derive a model to guide our estimation, both in terms of selecting appropriate regressors and of interpreting the coefficients of the final system. Our model has the following actors: A regulator and a profit maximizing LEC that invests in a single infrastructure variable, fiber, with a single product (local telephone service) and price (which, as mentioned, we will not observe). The regulatory agency has predetermined political leanings in favor of consumers or firms. The model, then, accommodates variation in local economic and regulatory conditions. The key assumptions in the model concern the relationship between infrastructure and final demand. We assume that infrastructure rotates outward the demand for telecommunications as it leads to the provision of new services. Increases in infrastructure have the feature of making the demand for telecommunications more elastic. Although this assumption makes intuitive sense for the technologies we study, ${ }^{7}$ it is nevertheless a strong parametric assumption. ${ }^{8}$ 
In particular if we let $Q$ represent quantity demanded then

$$
Q=f(I) g(X, P), \text { with } f_{I}(I)>0, \frac{\partial g(.)}{\partial P}<0
$$

where $\mathrm{X}$ represents a vector of location specific demographic and economic variables, I represents the installed level of fiber and $\mathrm{P}$ represents the price of final service. Consumer surplus is given by

$$
C S(P, X, I)=\int_{0}^{P} Q(I, X, p) d p=f(I) \int_{0}^{P} g(X, p) d p
$$

The effect on consumer welfare from infrastructure deployment is represented as either:

$$
\frac{\Delta C S}{C S}=\frac{C S\left(P, X, I_{2}\right)-C S\left(P, X, I_{1}\right)}{C S\left(P, X, I_{2}\right)}=\frac{f\left(I_{2}\right)-f\left(I_{1}\right)}{f\left(I_{2}\right)} .
$$

where $I_{1}$ and $I_{2}$ measure yesterday's and today's level of infrastructure deployment, or as

$$
\epsilon_{C S, I}=\frac{f_{I}(I) I \int g(X, p) d p}{f(I) \int g(X, p) d p}=\epsilon_{Q, I}
$$

The first formulation measures the change in consumer surplus attributable to infrastructure deployment as a percent of the end period's level, holding constant prices. ${ }^{9} T h e$ second measures the elasticity of consumer surplus with respect to infrastructure, also holding constant prices. Under our parametric assumptions, the elasticity of consumer surplus with respect to infrastructure deployment is the same as the elasticity of demand with respect to infrastructure.

Similarly, the historical effect on revenues from infrastructure deployment may be represented as: 


$$
\frac{\Delta R}{R}=\frac{P f\left(I_{2}\right) g(X, P)-P f\left(I_{1}\right) g(X, P)}{P f\left(I_{2}\right) g(X, P)}=\frac{\Delta C S}{C S}
$$

That is, the percentage change in revenue attributable to infrastructure deployment relative to final period's revenue is the same as the percentage change in consumer surplus. ${ }^{10}$ Similarly, the marginal revenue associated with another unit of infrastructure is

$$
\frac{d P Q}{d I}=P Q \frac{f_{I}(I)}{f(I)}=\epsilon_{Q I} \frac{P Q}{I}
$$

which provides one measure of the differences in returns to investment faced by different firms.

Under any specification, the key parameters are $\mathrm{f}(\mathrm{I})$ and $\epsilon_{\mathrm{QI}}$. The goal of our model is to use standard behavioral assumptions for firms and regulators to derive a minimal set of parametric restrictions for estimating $\mathrm{f}(\mathrm{I})$.

\section{Equilibrium interpretation.}

We assume that the regulator and the company play a Nash game. The regulator chooses price, while the company chooses the level of infrastructure. Each player chooses its optimal strategy holding constant the strategy of the other. In equilibrium, each is a best response to the other. We assume that the regulator maximizes a weighted average of consumer and producer surplus (current cash flow), while the firm maximizes the present value of the profit stream associated with investment. For pedagogical convenience, we also assume that digital infrastructure only enhances demand and does not change operating costs. This is plausible since most modernizing infrastructure investment has negligible influence on the marginal costs of providing telephone service, but does involve substantial installation expenses. ${ }^{11}$

Regulators choose prices to reflect the political disposition of the state and the locality. Their utility is given by: 


$$
U^{R}(X, P, I)=\theta \operatorname{CS}(X, P, I)+\Pi(X, P, I)
$$

where $\theta$ must be greater than zero (in our model's equilibrium it will be greater than 1 ), and where $I$ reflects the firm's cash flow, and is given by:

$$
\Pi(X, P, I)=P f(I) g(X, P)-W\left(I-I_{0}\right)
$$

where $I_{0}$ is the initial infrastructure level and $\mathrm{W}$ is the unit economic cost of infrastructure. ${ }^{12}$

Maximizing the regulator's utility (i.e., the regulator sets prices) yields:

$$
\theta-1=-\frac{g_{P}(X, P) P}{g(X, P)}=-\epsilon_{Q P}
$$

Regulatory optimization - as in (4) - implies that the equilibrium price - $\mathrm{P}^{*}$ - is a function of $\theta$ and $X$. The intuition is that regulators choose a price to achieve a desired elasticity of demand (in line with political demands as represented by $\theta$ ). ${ }^{13}$ Finally, substituting in (4) revenue for price $(P=R / f(I) g(X, P))$ we obtain

$$
R=-f(I)(\theta-1) \frac{g(X, P)^{2}}{g_{P}(X, P)}
$$

From (4a), then, we obtain that revenue is a function of $I, \theta, X$ and $P$. But from (4), $P$ is a function only of $X$ and $\theta$, making $R$ also a function only of $I, \theta$ and $X$. Equation (4a) implies also that the Nash equilibrium assumption is not necessary to estimate the revenue equation (4a). Thus, the estimation of (4a) is robust to any type of investment model assumed. ${ }^{14}$ That is, the estimation of (4a) can be done simply by (non-linear) two stage least squares, instrumenting for $\mathrm{P}$ and I. As we explain below, most of our estimates are simply various specifications for (4a). Thus, most of our analysis only requires implementing two stage least squares methods. 


\section{Regulation, prices, and political constraints.}

Prices, regulations, and political constraints vary across states. We modify the generic model in equation (4a) to account for such heterogeneity. Following quantitative models of telecommunications regulation, we make two assumptions (see, for example, Smart [1995]). First, regulators set prices based on $\theta$ and $X_{L}$, where the latter represents a vector of economic and demographic factors at the level of the LEC. Second, the bias towards customers, $\theta$, arises from a complex political process, taking place partially at the state level and partially at the LEC level. We measure several factors influencing this process. We label them economic and demographic variables at the LEC level, $\mathrm{X}_{\mathrm{L}}$, economic and demographic variables at the State, $\mathrm{X}_{\mathrm{S}}$, and other (partially observable) political variables at the state, $\mathrm{S}$. That is,

$$
\theta=T\left(X_{L}, X_{S}, S\right)
$$

Thus, substituting (5) into (4a), we can rewrite (4a) to obtain

$$
\log (R *)=\log f(I)+J\left(X_{S}, X_{L}, S\right)
$$

\section{Functional Form}

If we let $f($.$) be Cobb-Douglas, then$

$$
\log (f(I))=\gamma \log (I)
$$

implying that the elasticity of consumer surplus with respect to infrastructure, $\epsilon_{\mathrm{QP}}$, is given by $\gamma$. If we let $f($.$) be translog then$

$$
\log (f(I))=\gamma_{1} \log (I)+\gamma_{2}[\log \cdot(I)]^{2}
$$

implying that $\epsilon_{\mathrm{QI}}$ varies for different levels of I. $\epsilon_{\mathrm{QI}}$ is then given by $\gamma_{1}+2 \gamma_{2} \log (\mathrm{I})$.

With the Cobb-Douglas assumption the revenue equation (4b) becomes:

$$
\log (R *)=\gamma \log (I)+J\left(X_{L}, X_{S}, S\right)
$$

With the translog assumption the revenue equation becomes: 


$$
\log (R *)=\gamma_{1} \log (I)+\gamma_{2}(\log (I))^{2}+J\left(X_{L}, X_{S}, S\right)
$$

\section{Econometric considerations.}

We first propose to estimate our model using a two stage least square estimation of (4c), which allows us to obtain the returns to infrastructure deployment without imposing cross equation restrictions arising from a particular investment model. We start by specifying $\mathrm{J}\left(\mathrm{X}_{\mathrm{L}}, \mathrm{X}_{\mathrm{S}}\right.$, $S)=\delta^{\prime} X_{L}+\delta^{2} X_{S}+\delta^{j} S+\epsilon$. Thus, we estimate the Cobb-Douglas specification as

$$
\log (R *)=\gamma \log (I)+\delta^{1} X_{L}+\delta^{2} X_{S}+\delta^{3} S+\epsilon_{1}
$$

In equation (4d) $X_{L}, X_{S}$, and $S$ are exogenous, while $R$ and $I$ are endogenous. We instrument for I with $w$, where $w$ is a vector of exogenous LEC-specific infrastructure installation cost factors. $\gamma$ is the object of interest and is econometrically identified in the above. A similar and obvious argument holds for the translog specification for $f$, where two coefficients for $\gamma$ will be estimated.

Some related observations: First, estimating (4d) requires that prices not be a function of infrastructure, as we have assumed all along. ${ }^{15}$ Second, price elasticities are not identifiable from (4d), because $X_{L}$ plays a role in the determination of $\theta$ and in the determination of final demand. ${ }^{16}$ Third, the constants in $\mathrm{X}_{\mathrm{L}} \mathrm{X}_{\mathrm{S}}$ and $\mathrm{S}$ or $\mathrm{W}$ are not identified. Fourth, the argument leading to (4d) suggests that the list of control variables in $X_{L}, X_{S}$, and $S$ should be extensive, trying to capture factors influencing regional variation in telephone demand in the absence of digital infrastructure. Further, the factors measuring our basic demographic instruments must be exogenous to both the determination of $\mathrm{R}$ and $\mathrm{I}$. Fifth, the Cobb-Douglas function assumes that all LECs face the same infrastructure elasticity. This assumption is virtually a necessity for this study, since the data are not sufficiently rich to allow the estimation of LEC specific infrastructure elasticities. Sixth, there is no econometric guarantee that the estimate for $\gamma$ will be positive, though there is a presumption in the model that it is positive. ${ }^{17}$ Thus, a natural test for the infrastructure function is whether the estimated coefficient differs from zero. Seventh, the 
above specification presumes positive Is, as we use the expression $\log (\mathrm{I}) .{ }^{18}$ Finally, under the usual data limitations we cannot argue that we fully measure all infrastructure investment, and that our estimates imply that investment in fiber-optic cable by itself leads to some percent increase in revenues at all LECs. We can argue, however, that investment in fiber, which is one necessary part of digital infrastructure, positively correlates with investments in a whole range of digital technologies which are revenue enhancing. This precaution informs the interpretation below.

\section{Investment behavior}

To explore some of the features of investment we solve for the profit maximizing level of infrastructure under the assumption that the features of the environment which influence LEC investment do not change. This is the most natural model (of the many possible) for illustrating the determinants of cost. This is sufficient for our purposes since we do not use this investment model for any welfare inferences.

At time $t$, firms maximize the net present value of profits given by

$$
P V(I, X, P, W)_{t}=\sum_{s=t}^{\infty} \frac{P_{s} f\left(I_{s}\right) g\left(X_{s} P_{s}\right)-W_{s}\left(I_{s}-I_{s-1}\right)}{(1+\delta)^{s-t}}
$$

where $\delta$ is the firm's discount rate and W are LEC-specific factors that influence the cost of installing infrastructure. Assuming stationarity of $X$ and $\theta$ over time, and that $W$ is known, then by (4) $\mathrm{P}$ is then stationary, and we can solve (6) to obtain an optimal I at time t. ${ }^{19}$

The firm's first order condition with respect to $I$ is then given by

$$
f_{I}(I) g(X, P)=\frac{W}{P} \lambda
$$

where $\lambda$ is a term including discount rates and other factors. By substituting revenue for price, and performing other manipulations, equation (7) can be rearranged to yield 


$$
I=\frac{R \epsilon_{Q, I}}{W \lambda}
$$

From (7a), the equilibrium level of infrastructure, $I^{*}$, is a function of $W, \epsilon_{Q 1}, X$, and $P$ and discount factors. Assuming a Nash equilibrium, then, $\mathrm{I}=\mathrm{I}^{*}$ and $\mathrm{P}=\mathrm{P}^{*}$. By equation (4), $\mathrm{P}^{*}$ may be solved independently of the value of $\mathrm{I}^{*}$, while $\mathrm{I}^{*}$ must account for $\mathrm{P}^{*}$ by equation (7). Hence, assuming a unique solution from combining (4) and (7) and solving for $\mathrm{I}^{*}$ and $\mathrm{P}^{*}, \mathrm{I}^{*}$ becomes an implicit functions of $\epsilon_{\mathrm{Q}}, \mathrm{W}, \theta$ and $\mathrm{X}$, while $\mathrm{P}^{*}$ is an implicit function only of only $\theta$ and $\mathrm{X}$.

Although this model may be too simple to describe actual regulator/firm interactions, it is useful for estimating some of the basic determinants of installation costs. It also highlights identification issues in our econometrics estimation. If we wish to estimate (4d) simultaneously with an investment equation, then by (7a) it follows that we must estimate an investment equation of the form

$$
\log (I *)=\log (R *)+\log (\gamma)-\log (W)+\text { constant }
$$

where the above has assumed a Cobb-Douglas specification for $f(I)$. Letting $W=\alpha w+\epsilon$, we use non-linear three stage least squares to estimate (4d) and

$$
\log (I *)=\log (R *)+\log (\gamma)-\alpha w+\text { constant }+\epsilon_{2}
$$

If we estimate a two equation system consisting of (4d) and (7c), we not only improve the efficiency of our estimate of $\gamma$, but also, given the functional form and investment model assumptions, estimate the distribution of costs across firms, and their evolution. These additional benefits, though, come at a price because of the limited flexibility of equation (7c).

\section{Extensions to multiple inputs.}

Since many infrastructure technologies are complementary, it is important to measure infrastructure investment in several technologies simultaneously. Assume that two types of infrastructure, $\mathrm{I}_{1}$ and $\mathrm{I}_{2}$, influence demand. Let $\mathrm{Q}=\mathrm{f}\left(\mathrm{I}_{1}, \mathrm{I}_{2}\right) \mathrm{g}(\mathrm{X}, \mathrm{P})$ and $\mathrm{W}_{\mathrm{i}}=$ Cost of installing a 
unit of $I_{i}, I=1,2$. Then the investment decision has two first order equations,

$$
f_{I_{1}}\left(I_{1}, I_{2}\right) g(X, P)=\frac{W_{i}}{P} \lambda, \quad i=1,2
$$

Assuming a Cobb-Douglas formulation for $\mathrm{f}($.$) , and after performing various substitutions we$ obtain the system of equations which easily generalizes to more than two infrastructure variables:

$$
\begin{aligned}
& \log (R *)=\gamma_{1} \log \left(I_{1}^{*}\right)+\gamma_{2} \log \left(I_{2}^{*}\right)+\delta^{1} X_{L}+\delta^{2} X_{S}+\delta^{3} S+\epsilon_{1} \\
& \log \left(I_{i}^{*}\right)=\log (R *)+\log (\gamma)-\alpha w_{i}+\text { constant }+\epsilon_{2 i}, \quad i=1,2
\end{aligned}
$$

We only estimate the Cobb-Douglas specification of the infrastructure function for multiple inputs. $^{20}$

\section{Summary}

Our estimates will provide a measure of the impact of infrastructure deployment on consumer welfare. There are two key identification conditions. First, the determination of price, by whatever political and regulatory process, must occur independently of the level of infrastructure -- though the investment in infrastructure may be a function of price level. Second, telephone demand must be multiplicative in (almost) any function of infrastructure in order to lead to closed, simple and ultimately measurable relationships between revenue levels and infrastructure levels. These observations are useful for choosing instruments.

\section{Specification.}

We estimate three specifications of the basic system. Our basic specification for (4d), and (7c) when applicable, will assume a Cobb-Douglas benefit function and use the following variables:

$X_{L}=\{$ constant, log total LEC population, fraction LEC urbanized, fraction rural, log LEC per 
capita income, year dummies, small LEC (state employment in this LEC less than 10 percent), $\log$ population density, city of half million, city of quarter of million, fast growing area\}.

$X_{S}=\{$ constant, state GNP growth, log state/local per capita income, fraction of state employment in finance, insurance, and real estate $\}$.

$\mathrm{S}=$ \{constant, non-elected regulator, democrat majority of regulators, interaction of not-elected and democrat majority, vote for Dukakis in 1988, governor democrat, legislature democratic, legislature republican, govemor and regulator from same party, governor and regulator and legislature from same party\}.

$\mathrm{w}=\{$ constant, log of LEC construction wages, log of LEC level of construction employment, LEC growth in level of employment in construction, year dummies, holding company dummies, log of stock of fiber in 1986, translog in population and land $\}$.

In our second specification of the Cobb-Douglas benefit function we include nine holding company dummies in $X_{L}$. These dummies stand in for holding company specific differences in the growth of revenues. In our third specification we use the same covariates as listed above (without the holding company dummies), and estimate a translog. We only do this for fiber-optic cable, where the larger sample size describing firms's deployment of fiber yields sufficient degrees of freedom. For reasons explained below, each specification will be estimated on two different measures of revenue. One measures only local telephone revenue within the LEC. The other includes access charges from long distance telephone calls, which forms a significant fraction of many LEC's revenues. This results in six specifications for the estimation using only fiber optic cable and four specifications for the estimation using fiber, ISDN and SS7 together. We employ this number of specifications in order to explore the robustness of the inferences to different specifications.

\section{Data}

We undertake our analysis at the local exchange company at the sub-state level. Every RBOC has a state company and many states divide its telephone franchise territory between one 
of the RBOCs and other national and local companies. We use three main sources of information to understand these firms. For local-exchange company specific information and data on infrastructure we use an augmented version of the data developed by Greenstein, McMaster and Spiller [1995] (GMS) and Greenstein and Spiller [1995]. For data on political and regulatory variables we use the Book of the State published by the Council of State Governments, and we use the Yearbooks of the National Association of Regulatory Utility Commissioners.

GMS gathered demographic characteristics for each of the LEC's territories in each state for the period since divestiture. Because demographic information is available until 1992, and most of the relevant digital infrastructure data start to be reported in 1986, the GMS data set covers the period 1986-1992. GMS also gathered infrastructure statistics for all those LECs that file annually with the FCC. They file using forms M and ARMIS 43-03, 43-04 and 43-07 (Alaska, and Hawaii were excluded). There are 101 local exchange carriers in each year of the GMS data, ${ }^{21}$ which results in a data set with a maximum of 707 observations. The demographic information was collected at the county level, and was then assigned to the dominant carrier within its boundaries according to maps showing the local exchange carriers' territories in each state. ${ }^{22}$ The county data are then aggregated to the company level within each state. ${ }^{23}$ The main source of the demographic (county level) data is the Annual Estimates of the US Bureau of Economic Analysis, Department of Commerce, "Regional Economic Information Systems Annual CD," and the Bureau of Labor Statistics' Employment and Earning Annual Reports.

\section{Infrastructure.}

We construct our sample from the largest local exchange companies (LECs) within the United States at the sub-state level. ${ }^{2+}$ Data on miles of fiber optic cable covers 1986 until 1992 and is available for all companies -- RBOC, GTE, Contel, and many independents. ${ }^{25}$ Data on number of ISDN lines, ${ }^{26}$ and SS7 switches covers 1988 until 1992 and is only available for the RBOCs, GTE, Contel and very few independents. ${ }^{27}$ As described in the three previous footnotes, each of our infrastructure variables measures increasing digitalization of a modern telephone network.

All three of these infrastructure variables grew rapidly over our sample period (if 
somewhat unevenly across companies and across time) and continues to grow today. For example, the median number of fiber miles for all $101 \mathrm{LECs}$ in 1992 was 22,371. Most LECs increased the number of miles of fiber in their networks, with many smaller LECs starting from very low levels in the mid 1980s. The median multiple increase was four times from its level from 1988. The total number of fiber miles (this includes both "lit" and "dark" fiber) at the 101 LECs was 6,385,578 in 1992.

\section{Revenue.}

We supplement these data with information on LEC revenues, as reported to the FCC. This data are also collected as far back as 1986, but contain irreconcilable changes in definitions between 1987 and 1988. ${ }^{28}$ This is the most binding constraint on our sample. It begins with 1988 and ends in 1992. Many small independent LECs do not report revenue at all and a few do not do so until the later years in our sample. ${ }^{29}$

As a measure of a LEC's revenue we collected net operating revenue ("category 530" in the FCC reports), which contains both revenue for local calls and access charges. We also collected revenue for basic local service ("category 520" in the FCC reports), which contains no access charges but does contain several other miscellaneous categories of revenue. The first category of revenue more closely fits our model of LEC revenue. However, access charges form a significant fraction of LEC revenue and have recently been changing as they come under greater regulatory scrutiny and competitive pressure. We test the sensitivity of our results to the definition of revenue.

For each specification we will report two different estimates, one using all revenue and one using only local revenue. Among the balanced panel, casual inspection shows some variation in revenue from one year to the next, but on average very little change in inflation adjusted levels of revenue at most LECs over the five years. About half the sample saw an increase while the other half saw a decrease -- usually this was not more than 5-10 percent in either direction, but a few LECs did experience as much as $20 \%$ change in revenue.

\section{Local and State demographics.}


Local and state demographic and economic variables come from the BEA reports for economic activity at the county level. We matched these reports against LEC territory maps, as explained in GMS [1995]. This provides data on total population, their composition, wages, employment and other economic activity at the LEC level.

For the instruments in the two-stage least square estimates and for our marginal cost equations we use different features of construction markets - their size, level of wages and recent growth. The measure of size controls for scale, construction wages controls for construction costs, and construction employment growth controls for capacity constraints or downturns that either raise or lower expenses. We include time dummies to reflect widely reported declines in the costs of inputs and installation, particularly among fiber and ISDN. We include holding company dummies to reflect differences in the ability of firms to install digital equipment. We exclude the independent company dummies in the full sample and Contel and the independent dummies in the partial sample. We include multiplicative specifications of costs in land and population, reflecting both economies and diseconomies in network configuration. These scale economies and diseconomies are associated with population size and geographic scope of service territory. We also estimate an equation with inherited fiber in 1986; this stands in for inherited costs advantages in installing digital equipment.

For our revenue equation, we include total population and some of its features from BEA estimates. The US census distinguishes between urbanized, suburban and rural population. Suburban population lives in cities between five and fifty thousand total population. We include the fraction of the population of each type and exclude the fraction suburban. From BEA data we include local per capita income, state per capita income, population density, state growth, and the fraction of the state economy devoted to FIRE (finance, insurance and real estate). All these measure the propensity of population and regional economy to use more telephone services and political pressure to increase or decrease prices. We also include a dummy for whether a LEC is very small (covers less than 10 percent of the state's employment); we expect these small LECs to be predominantly rural and protected by the regulatory process with higher prices or higher access charges. We include time dummies, omitting the initial year.

We also add a dummy for whether the LEC contains a city within its boundaries with a 
population over half a million, according to the 1990 US Census. ${ }^{30}$ While these areas are geographically minute relative to a typical LEC geographic territory, they play a central role in many regional economies, drawing population from surrounding territory daily for work, serving as the hub and coordinator of much outlying economic activity in the periphery. We also use a dummy for whether the LEC contains a city over a quarter million. Finally, we add a dummy for whether the LEC covers an area designated as one of the fifty fastest growing SMSAs in the US in the 1980 s, again from the US census. ${ }^{31}$

\section{Political variables.}

For every year we collected the political affiliation of all state regulators in the state agency in charge of telecommunications, if known; otherwise we report the political party of the govemor that appointed the regulator. The source is the Yearbooks of the National Association of Regulatory Utility Commissioners. We used the Book of the States (VOL 25-29), Tables 2.1 and 3.2, for counts for the political affiliation of every legislator in the house and sente, as well as the governor. We dropped Nebraska and Washington DC from the sample because neither contains a bicameral legislature. ${ }^{32}$ We include dummies for whether democrats are a majority in the state regulatory agency or not. ${ }^{33}$ We also include dummies for whether the regulators are elected on not (appointed $=1$ ), as positive political theory predicts that the method of appointment should influence telecommunications regulatory behavior (See e.g., Smart [1995]). We also interact regulatory majority with election/appointment.

We further include the fraction of the popular vote for Dukakis in 1988 as a measure of the political leanings of the state. Further, we include three dummies for the political affiliation of the governor (Democrat $=1$ ) and also for the legislature when both houses are from the same party. The omitted category is any non-aligned legislature. Finally, we include two dummies for political alignment, which may influence the ease with which political institutions make changes and commitment to regulatory policy and indirectly determine a firm's revenue (see Smart [1995], and Levy and Spiller [1994]). One dummy takes on the value of one when the regulatory agency and the governor are from the same party, the other takes on the value of one when the regulatory agency, the govemor and the legislature are from the same party. ${ }^{j+}$ 


\section{Final data set.}

After applying the selection criteria described above, the full sample (containing information only about fiber) has 458 observations for 1988-1992. The partial sample (containing information about fiber, ISDN and SS7) has 308 observations for 1989-1992. Both are unbalanced panels, with complete observations for the RBOCs and GTE, and many incomplete observations for other independents. Table 1 reports descriptive statistics for all endogenous and exogenous variables, putting the instruments in the same category as local demographic variables. We also report the infrastructure variables for the partial sample. Since there were no significant differences between the descriptive statistics for the exogenous variables for the full and partial sample (except in the firm dummies, as noted), we only report the results for the full sample.

\section{Estimation and results}

7

Since the two and three stage estimates of the revenue equation are not that different, we focus on the two stage least square estimates for most of the discussion and present the three stage least square results at the end to discuss the cost side. The larger sample $(N=458)$ is used for the model using only fiber. The smaller sample $(\mathrm{N}=308)$ estimates the model using fiber, ISDN and SS7. Since we estimate the model on these unbalanced panels we interpret the estimates accordingly. We view each year's cross section of data as providing independent observations on the same underlying relationship. Each Table presents four sets of estimates, two different specifications of revenue equation for two different revenue variables. Thus, all of our conclusions about welfare results from infrastructure are supported by either set of the revenue equation estimates. Only the conclusions about cost indexes require the cost equations in the three stage estimates.

\section{Revenue equation estimates}

In Table 2 the infrastructure coefficient (only on fiber), which we interpret as the elasticity of demand with respect to fiber, is significant and large. The estimates range from 0.06 
to 0.11 . The coefficients on fiber are always positive and significant. The first two columns of Table 1 in the appendix presents translog estimates for the basic specification and we summarize the results in the bottom of Table $4 .{ }^{35}$ The range of the estimates do not differ much from their values in Table 2, where the elasticities were assumed constant across all specifications. Hence, we conclude that the translog specification for fiber adds little additional information in this specification.

We now turn to the multiple infrastructure estimates, found in Table 3 and summarized in Table 4. Table 3 contains even higher estimates for elasticity for fiber than in Table 2, ranging from 0.08 to 0.18 . The coefficients on ISDN are always positive and only significant when we include the holding company dummies. Their low value is zero and their high is 0.16 in column 3 of table 3 . The coefficients on SS7 are always negative except in column 4 . This may indicate that investment in SS7 is too positively collinear with investment in ISDN and fiber to be informative. These results may also indicate that the bulk of the diffusion of SS7 and ISDN takes place too late in our data to have much effect on revenue. Updating this to more recent years could yield quite different estimates, if recent publicity is to be believed. Further explorations with translog specifications did not yield any additional insight and are not shown. ${ }^{36}$ In the discussion below we explore the implications of the magnitude of these estimates and their interpretation. A conservative conclusion so far is that fiber infrastructure contributes to enhancing demand, but that the others, by themselves, do not do so at all or not greatly.

We now discuss the estimates of the coefficients on the controls, which do not largely differ between Tables 2 and 3 . The control variables help predict revenue, largely in the predicted direction. We first briefly review local demographics. Total population does increase revenues, but at an elasticity less than one. Higher fractions of urbanized and rural populations do lead to higher revenues (relative to suburban populations), but the coefficient magnitudes are usually higher for the rural areas in most estimates; in other words, trading a set fraction of urbanized for rural population, holding constant population size, increases revenue. However, trading either one for a moderately small town will decrease revenue significantly. Small territories have higher revenue, probably reflecting higher prices going to small rural areas. Population density is never significant. The time dummies and sometimes the city hubs dummies (city with one quarter 
million) generally have the expected signs and are often significant. The time dummies indicate a secular decline in revenue over time in the absence of other changes, though they vary widely in their rates from one set of estimates to another. It is also difficult to make any robust inferences from the LEC dummies in the revenue equation.

Of the state demographics, the log of state to local per capita income keeps its sign and significance, though it varies in range. It says that the LEC benefits most when its per capita income is much higher than the state average, and benefits least when the LEC is much lower than the state average. When they are roughly the same, as when one LEC dominates most territory within a state, then there is little effect. This coefficient perhaps indicates that the LEC with much higher per capita income for the state contains concentrations of high-income generating economic activity for the state, such as would be found in the major city within a state. The coefficient on finance, insurance and real-estate activity (FIRE) also tends to be positive and significant in most specifications, as expected. The difference between being in the high and low FIRE state can have a large influence on LEC revenue. ${ }^{37}$ State GNP growth does not matter.

The coefficients on political variables contain several interesting estimates. First, revenues are lowest when elected republicans are in charge of the regulatory commission, when revenues may be lowered by as much as $30 \%$ or more. In all other situations (including appointed republicans), the commission has roughly the same effect on revenues. Revenues are also lower in states with high votes for Dukakis, but the magnitude of the effect is not too large except between the extremes. Between the extremes revenues can vary as much as $40 \%$ (from 0.34 to 0.56 , Utah and Massachusetts, respectively). None of the remaining political variables are statistically significant in Table 2 and 3 , though we note hints of several intriguing patterns. ${ }^{38}$ Summarizing the state political variables, it seems that the regulatory agency and the political leanings of the state have the largest effect on revenue, but the political affiliation of the different . state actors also plays a role in some circumstances. We have more to say in the analysis below, but we conclude tentatively that the political variables are important control variables to include in the specification. 


\section{Calculating buyer and seller benefits from infrastructure investment}

We now use our coefficient estimates to calculate the benefits to producers from actual infrastructure investment. We calculate the change in a period's demand attributable to (actual) infrastructure relative to some base demand year. We calculate this for every LEC in our sample and then present summaries of these calculations. This calculation assumes that prices do not change (e.g., because regulators compel it), which makes these estimates too optimistic if postinvestment prices fall or too pessimistic if they rise (from the LEC's perspective). ${ }^{39}$ As noted in the earlier section, this is not a true profit calculation, since we are not accounting for costs of infrastructure deployment, nor are we accounting for anticipated changes in prices (i.e., anticipated by the firm) in response to infrastructure deployment.

We also noted above that we may use the same measure to calculate the benefits to consumers from actual infrastructure investment. This same measure provides the change in consumer surplus attributable to infrastructure deployment relative to a base year. For consumers this calculation is too pessimistic if post-investment prices actually fall or too optimistic if they actually rise.

Table 5 presents estimates of the welfare benefits from infrastructure investment, using the estimates from Table 2 and Table 3. These are conservative estimates, using the low estimates from each table. In each case, we show the estimates we use. Since we have data on fiber investment for all 101 LECs who report to the FCC, we use the whole sample (which is slightly larger than the sample used for estimation of the coefficients). ${ }^{40}$ This table compares 1992 with 1988. The next set of calculations uses a midrange estimate for fiber and a low estimate for ISDN. We exclude SS7 since it is rarely significantly different from zero. We have less data on ISDN for the 101 LECs. We are only able to make these calculations over 82 LECs (which is also slightly larger than the sample used for estimation). ${ }^{+1}$ These two sets of calculations compare 1992 with 1989.

In all the simulations in Table 5, the percent demand due to infrastructure investment is substantial. Table 5's estimates show 10 percent of LEC demand on average was due to investment in fiber. The median percent was 9 percent, indicating little skewness in the benefits across LECs. In the simulations using two infrastructure estimates, the estimates of the gain from 
infrastructure investment are much higher than in Table 2. This is partially a result of the higher coefficient estimate for fiber (.11 vs .07), but also due to the addition of one more type of infrastructure, ISDN. The mean and median increase in demand is 13 percent, with considerable range of experiences across the LECs (s.d. $=.08$ ).

These are large estimates. As a consequence, we can not reasonably argue that investment in ISDN and fiber-optic cable by themselves were responsible for over ten percent of revenue enhancement at all LECs. It is more likely that activity in a whole range of digital technologies accompany investment in fiber and the totality of all this investment was demand enhancing. Moreover, we cannot say how much demand enhancing investment was or was not captured by the LEC due to regulated changes in prices. However, our estimates do appear consistent with industry consensus that in the absence of LEC investment in new technologies, revenues would have fallen in many localities.

We now discuss the implications of Table 5 for inferences about consumer welfare. In all the estimates, the enhancement to consumer surplus from infrastructure investment is the same as the demand elasticity, which is large. Thus, we conclude that a high percentage increase in consumer surplus, as much as a ten percent or more, is due to recent investment in digital infrastructure investment and the investment activities correlated with it.

Since an estimate of the percentage surplus attributable to infrastructure is scale free, it is difficult to interpret without any base estimate for total consumer surplus, which is not recoverable in our model. For expository ease we translate our estimate of the elasticity of consumer surplus to infrastructure into its price-equivalent change. More specifically, for a constant elasticity of demand -- that is, $Q=\operatorname{Af}(\mathrm{I}) \mathrm{P}^{-e}-$ - we calculate the extent to which prices must have declined to provide the same consumer surplus change as provided by actual infrastructure investment, fixing I at its later value. If the estimated percentage increase in consumer surplus due to infrastructure investment is given by $\% \mathrm{dC}$, then the percentage price decline that provides the same amount of consumer surplus is given by $\% \mathrm{dP}=[1-\% \mathrm{dC}]^{\{(1 /(-e))}-$ 1 , where $\mathrm{e}>1$ is the elasticity of demand. ${ }^{42}$ Since we do not know the value of the elasticity of demand, we calculate $\% \mathrm{dP}$ under different assumptions about demand elasticities (i.e., e $=1.5,2$ or 2.5). This is sufficient for our purposes, which is to illustrate the degree of the welfare changes 
implicit in the estimates.

These calculations are also in Table 5. Not surprisingly, as demand becomes more elastic a smaller price decline achieves the equivalent amount of consumer surplus. At most LECs the increase in consumer surplus is equivalent to a decline of prices on the order of 12 and 8 percent if demand elasticities are 2.0 and 2.5. The median is smaller, 10 and 6 percent respectively. The estimates from Table 3 lead to higher gains to consumers than the estimates from table 2 . Once again, looking at the conservative estimates that exclude SS7, we see that the price equivalent declines are 15 and 10 percent if demand elasticities are 2.0 and 2.5. For the elasticity of 1.5 the equivalent price declines are much larger, but are not shown. ${ }^{43}$ No matter how we calculate it, these gains are equivalent to substantial price declines. Since these are conservative methods we conclude that the welfare benefits from infrastructure investment during the 1988-1992 period were large.

\section{The marginal returns from infrastructure investment}

Our model also provides insight into the diffusion of advanced digital infrastructure by quantifying the LEC's incentives to invest in more infrastructure. We can use our static model to examine the marginal benefit to the LEC from more infrastructure. Under the Cobb-Douglas specification $\mathrm{dR} / \mathrm{dI}=(\mathrm{R} / \mathrm{I}) \epsilon_{\mathrm{QI}}$, where we estimate $\epsilon_{\mathrm{Ql}}$. A similar calculation for the translog also can be done. While investments in sunk assets are not entirely a static problem for the LEC, this "as if" exercise still yields useful insight into the incentives influencing the diffusion of digital infrastructure. This exercise only requires estimates of $\gamma$ and not cost estimates.

Table 6 presents the estimates for different values of the elasticity of demand with respect to fiber. The first three estimates show different values for $\gamma$ that span the lower range of infrastructure elasticity estimates found in tables 2 and 3 . The last shows a comparison with the translog estimates from Table 1 in the appendix. The table calculates the returns to one year's revenue from an additional "fiber-mile", standardizing in 1987 dollars. The table only examines the LECs owned by the Regional Bell Operating Companies, who did most of the investment in fiber in the United States.

The table shows that for a low estimate of the elasticity to infrastructure by 1992 the 
median marginal return on another fiber mile was $\$ 662$ in current revenue for our lowest estimates of alpha. Even among the RBOCs there was considerable variation in these returns. The first quartile received $\$ 472$ and third $\$ 835$. The mean is slightly higher than the median, showing a slightly skewed distribution. For the higher estimates of $\gamma$, the same patterns holds with all values increasing proportionately.

The Table shows a dramatic the change over the five year period. The median marginal return falls rapidly over the period. By 1992 it is at one quarter its level of 1988 . This pattern does not depend on the estimate for $\gamma$ (partly due to the Cobb-Douglas assumption we use for $f(I)$ ). The variation also declines sharply across all the LECs over the same period, again irrespective of the estimate of $\gamma$ we use. This change largely reflects the reduction in the amount of skewness in marginal returns. The LECs are becoming more alike over time.

In the bottom we present the same simulations using the most conservative translog estimate (where the mean elasticity is 0.6 over the sample and growing slightly over time). The results do not differ much from the Cobb-Douglas specification in their main qualitative features. The marginal retums to infrastructure fall dramatically over time and the range across firms also falls, though the magnitudes do differ somewhat. Hence, we conclude that these patterns are not a feature of the functional form we assume for the benefit function.

These estimates are consistent with a relatively straightforward diffusion model. As the user-costs of installing infrastructure fell rapidly over the period, phone companies installed the lower cost input deeper into their network, into places where its marginal return was lower. It is reasonable to conjecture that the narrowing marginal returns are being driven by learning, experience and knowledge spillovers. As all companies became familiar with the new technology, the opportunities for investment necessarily narrowed between companies.

\section{The "friendliness" of different states}

The final interesting feature of the revenue estimates is associated with the political variables. In our simple model of revenue, the factors associated with political factors measure the state's regulatory stringency. This stringency then influences prices and revenue. This line of causation is distinct from economic and demographic factors, which influence both the political 
motivation for setting a level of prices and the aggregate quantity demanded at a certain price level.

The theoretical model suggests that we may break out the component of revenue associated with the political factors in the state. Table 7 shows our implementation for 1988 and 1992.Using table 2, we compute the sum of the "political" coefficients multiplied times the variables for each state. ${ }^{44}$ We then take the difference between this sum and the maximum for that year, standardizing the "friendliest" state at zero. We determine the rank of the state in that year by the average of the estimates from the two columns. We do this for all jurisdictions except Nebraska and Washington D.C. ${ }^{45}$ For comparison, we also show the Merrill-Lynch rankings for regulatory friendliness towards electrical utilities, as used by Joskow, Rose and Wolfram [1996].

These estimates show large differences between states in the degree of friendliness. The difference between the minimum and the maximum is as much as -.5 in some estimates, which translates into over a $30 \%$ decline in revenues due to political variables. The mean is generally around -.25 , which translates into a $16 \%$ decline in revenue. These differences will have a large influence on infrastructure investment behavior and the returns to infrastructure under any investment model. Under the investment model proposed in (7b), for example, the effects of regulatory friendliness would be quite pronounced. ${ }^{46}$ We conclude that this index is indirect evidence that the regulatory environment has an important quantitative effect on company investment in infrastructure.

The Tables shows stability in the ranking of states over these five years. Most of the changes reflect changes in the state political actors. The states that stay in the top fifteen in both samples are Alabama, California, Delaware, Idaho, Illinois, Maine, Mississippi, Nevada, South Carolina, and Utah. The states that stayed in the bottom fifteen in both years are Colorado, Louisiana, Maryland, Missouri, New Jersey, New York, Oregon, and South Dakota. No states moved from the bottom to the top. The states that move from the top to bottom include North Carolina and Oklahoma. This relative stability in state rankings, combined with the effect the regulatory environment can have on investment -- as shown above -- is intriguing empirical evidence for the commitment to regulatory policies by potentially changing political institutions. As a related aside, we have generally found that in any given year our index does not correlate 
with the Merrill-Lynch index for electrical utilities. ${ }^{47}$

These results, while admittingly a crude measure of regulatory friendliness, do suggest the importance of political factors in shaping the environment in which firms invest. We suspect, however, that we are reaching the natural limits of our reduced form approach to variation between political institutions. With more time-variation or perhaps more structure on the model of regulatory mechanisms, further research may be able to identify the influence of political actors and institutions with more precision.

\section{Cost equation estimates}

Several different estimates of the investment equation were estimated. Appendix 2 and 3 contain the revenue and investment equations for the Cobb-Douglas specifications shown previously. Appendix 2 estimates this only for fiber on the full sample. Appendix 3 shows estimates for a multi-input specification using only fiber and ISDN, not SS7. SS7 was excluded based on the results in Tables 3, which indicated that the elasticity on SS7 was rarely positive or non-zero. An investment equation was also added to the basic specification of the translog benefit function. These are shown in columns 3 and 4 of Appendix 1 along with the other translog estimates. Table 8 summarizes the main findings.

The firm dummies identify large differences in the costs of installing fiber. The results are summarized in Table 8 where the coefficient estimates have been transformed into their corresponding cost index values. These indexes do not represent the full cost of installing infrastructure, only the costs that are not otherwise accounted for by other variables, but vary over time or across firms. We present a range of estimates, reflecting the extreme highs and lows among the variety of specifications.

Table 8 does not indicate that the RBOCs (Regional Bell Operating Companies) have much lower costs than the Contel, GTE or the independents. The firm dummies differ too much across specifications to draw such a conclusion. However, among the RBOCs, Bell Atlantic, Nynex and Pacific Bell all have lower costs for installing fiber than the remaining firms. The degree of cost advantage, however, differs widely across specifications and samples. For ISDN, the RBOCs have much lower costs than either GTE or Contel. 
The time dummies, as expected, indicate a large secular decline in the cost of installing fiber. Table 8 shows an $80 \%$ decline in costs over five years when the full sample is used, while it shows over a $64 \%$ decline over four years from the partial sample. This accords with the observed behavior and publicity about some of the large investment programs recently undertaken by LECs. It is also consistent with the results in Table 6 showing a decline in marginal revenue over time. In addition, Table 8 shows a decline in the costs of ISDN of over $85 \%$ over four years, also consistent with the recent gain in momentum to diffuse ISDN to business users.

Certainly the rapid fall in these estimates partly reflects that the true economic costs of installing digital technologies, including the costs of material and construction, came down dramatically in the late 80 s. However, since the price of materials associated with fiber optic cable and related technologies (such as repeaters) was not falling as rapidly over this time period ${ }^{48}$ material prices alone cannot form the entire explanation. Thus, we conjecture that our estimates reflect the joint workings of many secular factors that influence the costs of installation, including, but not restricted to the cost of materials, like declines in the costs of acquiring knowledge on how to install new technologies efficiently and quickly; experience in solving installation problems; costs of training, and other factors that influence the user cost of installation. Further, we suspect that this reflects a well-known feature of fiber in the local loop -the first strands are the most difficult to lay along any given route, but once these initial costs are sunk, additional fiber miles are much easier.

Despite these dramatic changes, secular declines in cost are not the only factor at work explaining heterogeneity on the cost side. Other implications about costs come directly from appendix 2 and 3. In virtually every estimation the land and population variables are significant. In fiber there are increasing costs in larger territories and decreasing costs in larger populations (over the relevant ranges of the data). However, these scale effects eventually slow at very high population levels or large territories and definitely interact. ISDN shows weak diseconomies in large population areas, though no sensitivity to geographic size.

The performance of the remaining cost variables is mixed. Overall the variables on construction markets does not predict the costs of laying fiber except in appendix 2's estimates. 
There, higher wages raise the cost of installation, as does recent growth in construction markets (perhaps reflecting capacity constraints). Construction market variables also do not predict the costs of installing ISDN. It is also interesting to note that the inherited experience from a high stock of fiber in 1986 does seem to provide advantages across all the types of infrastructure investment. According to Appendix 2, it seems to lower the costs of installing fiber. According to appendix 3 , it does not seem to influence the costs of installing fiber, but it does lower the costs of installing ISDN.

\section{Conclusion}

When economic policy focuses on information infrastructure, the presumption has been that more is better. While this may be right to the first order, in this paper we claim that whether it is right or not will only be known from detailed case studies.

In this study we examined investment in fiber optic cable, ISDN lines and signal seven software, infrastructure which plays an essential role in bringing digital technology to local telephone networks. We chose to study local telephone service because these are an important set of users and investors in the burgeoning "information super highway." We estimated a model composed of a regulator and an LEC, that allowed us to estimate the elasticity of final user demand for infrastructure investment by their LEC, controlling for factors such as local economic activity and the political disposition of state regulators.

In all our estimates we find that consumer demand is sensitive to investment in modern infrastructure as represented by fiber optic cable. We find that, as of 1992, fiber-optic cable enhances LEC demand. Sometimes our estimates show that ISDN lines do as well, but SS7 generally does not. The estimated elasticity of consumer surplus to fiber optic deployment is never less than 6 percent and much higher in some estimates. The elasticity of demand for ISDN ranges widely between zero and 16 percent. The elasticity for SS7 is rarely robustly estimated. In all our estimates these magnitudes lead to the conclusion that infrastructure investment is responsible for a substantial fraction of the growth in consumer surplus and business revenue.

As far as local telephone markets are concerned, we see many research aspects to develop further. We have subsumed the regulatory behavior into our reduced form estimates and not used 
reported information on the diffusion of regulatory reforms and their adoption by state agencies. Nor have we fully modeled the complex dynamic bargaining that goes on between state regulators and LECs over infrastructure and pricing. Infrastructure expenses are (literally and figuratively) sunk, while regulatory agencies might offer only weak commitments to LECs to recover revenue on these investments. Finally, in this paper we have only characterized consumer heterogeneity in a reduced form way. Providing more structure could help us identify the different effects of infrastructure deployment on business and residential consumers, urban and rural customers, etc. Separating these effects should help us identify the magnitude of the welfare returns to consumers and producers from infrastructure investment, and sharpen the policy implications.

Besides local telephone networks, many related information technology markets are potential subjects for the study of the benefits associated with new digital technology. It is well known that the long distance telephone companies and the competitive access providers have made extensive investments in fiber optic cable and related digital technologies. It is also well known that private firms are also making large investments in user-owned networks, which combine computing and communication technology in user-customized arrangements. These digital networks are both complementary and substitute to the public infrastructure network, further increasing the complexity of any welfare analysis. Only such careful studies will reveal whether the results we found for local telephone markets hold for other modern digital infrastructure in a wide array of markets. 


\section{References}

Bresnahan, T. F. [1987], "Measuring the Spillover from Technical Advance: Mainframe Computer in Financial Services," American Economic Review, March. pp 742-755.

Bresnahan, T.F. and R. Gordon [1996], The Economics of New Goods, University of Chicago Press.

Brown, K. and S. Greenstein [1995], "How much Better is Bigger, Faster \& Cheaper? Buyer Benefits from Innovation in Mainframe Computers in the 1980s." NBER Working Paper number 5138

Congressional Budget Office [1991], How Federal Spending for Infrastructure and Other Public Investment Affects the Economy, Washington DC: Government Publication Office.

Cronin, F. J., E. K. Colleran, P. L. Herbert, and S. Lewitzky, [1993a], "Telecommunications Infrastructure Investment and Economic Development," Telecommunications Policy, August, pp $415-430$

Cronin, F. J., E. K. Colleran, P. L. Herbert, and S. Lewitzky, [1993b], "Telecommunications and Growth, The Contribution of Telecommunication Infrastructure Investment to Aggregate and Sectoral Productivity," Telecommunications Policy, December. pp 677-690.

Dholakia R. R., and B. Harlam [1994], "Telecommunications and Economic Development: Econometric Analysis of the US Experience," Telecommunications Policy, 18(6), pp. 470-477.

Deiwert, E. [1986], The Measurement of the Economic Benefits of Infrastructure Services. Lecture Notes in Economics and Mathematical Systems Series Vol.278.

Greenstein, S., S. McMaster and P. T. Spiller [1995], "The Effect of Incentive Regulation on Local Exchange Companies' Deployment of Digital Infrastructure," Journal of Economics, Management, and Strategy,

Greenstein, S., W. Sosa-Escudero and P. T. Spiller (1996) "The Adoption of Regulatory Reform in Post-Divestiture Local Telecommunications Rule-Making." Mimeo, University of Illinois.

Greenstein, S and P. T. Spiller [1995], "Modern Telecommunications Infrastructure and Economic Activity: An Empirical Investigation." Industrial and Corporate Change, 4(4), pp. 647-665.

Hardy, A [1980], "The Role of the Telephone in Economic Development," Telecommunications Policy, 4(4), pp 278-286. 
Hendel, I. [1995], "Estimating Multiple-Discrete Choice Models: An application to Computerization Returns," Technical working paper no 168, NBER, Oct.

Hausman, J. And T. Tardiff [1995], "Valuation and Regulation of new Services in Telecommunications," mimeo.

Huber, P., M. K. Kellog, and J. Thorne [1993], The Geodesic Network II: 1993 Report on Competition in the Telephone Industry, Washington DC, The Geodesic Company, 1993.

Joskow, P, N. L. Rose and C. D. Wolfram [1996], "Political Constraints on Executive Compensation: Evidence from the Electric Utility Industry," Rand Journal of Economics, 27 (1), pp165-182.

Kahin, B. [1991], Building Information Infrastructure: Issues in the Development of the National Research and Education Network, McGraw-Hill.

Kraashauer, J, various years, Fiber Deployment Update, Federal Communications Commission, Washington DC.

Lehr W. and R. Noll [1989], "ISDN and the Small User: Regulatory Policy Issues." CEPR Working Paper \# 175, Stanford University.

Levy B. and P Spiller [1994], "The Institutional foundation of Regulatory Commitment: A Comparative Analysis of Telecommunications," Journal of Law, Economics and Organizations.

Lewis, T.R. and D.E.M. Sappington [1991], "Oversight of Long-term Investment by Short-lived Regulators,"32, No.3, International Economic Review, pp:579-600.

McMaster, S. [1995], Telecommunications in a new era of Competition: Fiber Optics, Regulatory Barriers, and Competition, Unpublished Dissertation, University of Illinois.

Munell, A. H. [1992], "Infrastructure Investment and Economic Growth," Journal of Economic Perspectives, 6(4), Fall, pp. 189-198.

Mueller, M. [1993], "Telecommunications as Infrastructure: A Skeptical View," Journal of Communications, 43(2), Spring, pp. 147-159.

National Research Council [1996], The Unpredictable Certainty, Washington, D.C.: National Academy Press.

Roller, H. and L. Waverman [1996], "Endogenous Growth and Telecommunications infrastructure Investment," mimeo, OECD, May 1994. 
Saunders, R., Warford, J. and Wellenius, [1983], Telecommunications and Economic Development, Baltimore, MD: John Hopkins University Press.

Selander, H. [1990], "The Economics of Fiber to the Subscriber," Public Utilities Fortnightly, August 16, 1990

Smart, S., [1995], "The Consequences of Appointment Methods and Party Control for Telecommunications Pricing," Journal of Economics and Management Strategy.

Spiller, P.T., and S. Urbiztondo, "Political appointees vs. career civil servants: A multiple principals theory of political bureaucracies," 10, European Journal of Political Economy, pp:465-497.

Tardiff, T., and W. Taylor [1993], "Telephone Company Performance under Alternative Forms of Regulation in the US," Working Paper, NERA, Cambridge MA., September, 1993.

Taylor, W., Zarkadas, D. Zona. [1993], "Incentive Regulation and the Diffusion of new Technologies in Telecommunications," Ninth International Conference of the ITS.

Teske, P. [1995], American Regulatory Federalism \& Telecommunications Infrastructure, Hillsdale, NJ: Lawrence Erlbaum Associates.

Trajtenberg, M. [1990], Economic Analysis of Product Innovation, The Case of CT Scanners, Harvard University Press, Cambridge MA.

Williams, F. [1991], The New Telecommunications: Infrastructure for the Information Age, New York: The Free Press.

US Department of Commerce [1991], The NTIA Infrastructure Report: Telecommunications in the Age of Information, NTIA special publication, 91-26, Washington, DC: Government Publication Office.

Yates, Marshall [1990], "Promise of Fiber Optics," Public Utilities Fortnightly, August 16, 1990. 


\section{ENDNOTES}

1. There is a relatively developed literature on the influence of telecommunications infrastructure investment on developing and rural economies. This literature is usually concerned, however, with the level of penetration rates and quality of basic service. See, for example, Hardy [1980] or Saunders et al [1983]. Reviews of earlier work in telecommunication are usually about modernizing the post-WWII US telephone system. See Mueller [1993] for a "skeptical" review. Also see Roller and Waverman [1994] for a cross-country comparison closer to our focus on modern telecommunications networks.

2. For a variety of perspectives on information infrastructure policy see Commerce Department, NTIA [1991], Kahin [1991], National Research Council [1995], Teske [1995], Williams [1991]. For further discussion of policies associated with inducing telecommunications infrastructure investment, see Greenstein, McMaster and Spiller [1995], Huber [1993],'Kraashaur [1995], Lehr and Noll [1989], McMaster [1995], Selander [1990], Tardiff and Taylor [1993], Taylor, Zarkadas and Zona [1993], or Yates [1990].

3. See Bresnahan [1987] for an analysis of the impact of computers on the financial services industry; Hausman and Tardiff [1995] for an analysis of the demand for Voice Messaging Services in telecommunications; Trajtenberg [1990] for an analysis of the returns to hospitals from improvements in CT scanner technology; Hendel [1995] for an analysis of the bennefits to business users from improvements in PC technology; and, Brown and Greenstein [1995] for an analysis of large computer system user benefits from technical change.

4. See Munell [1992] Aschauer [1990], Deiwart [1986] and Greenstein and Spiller [1995] for a broader review of infrastructure studies inside and outside of telecommunications.

5. DRI used an input/output approach to measure the contribution of telecommunication to economic efficiency, in particular, improvements in sectoral total factor productivity. DRI estimates that there was a $\$ 46.5$ billion dollar resource saving (in 1990 dollars) due to increased efficiency in the supply of telecommunications equipment and service (see Cronin et al [1993a, $1993 \mathrm{~b}]$ ). They find that about $25 \%$ of productivity growth over the late 1970 s to 1990 s was attributable to improvements in telecommunications productivity and consumption efficiencies. These effects are especially pronounced in finance, transportation, trade, real estate and petroleum refining. Cronin et al [1993a] perform a similar analysis for a more disaggregate sample, a cross section of counties in Pennsylvania, and confirm the findings made with more aggregate data.

6. Dholakia and Harlam [1994] examine variation in telecommunications quality across the 50 states. They find a positive relationship between investment in telecommunications and economic activity, controlling for other factors such as state education, energy consumption, and other inputs to the local economy. In a predecessor to this paper's study, Greenstein and Spiller [1995], using the same unit of analysis as in this paper, examine the influence of telecommunications infrastructure on local economic activity in two sectors, finance, insurance 
and real-estate (FIRE) and manufacturing. They find that modern infrastructure is associated with large increases in FIRE, but not manufacturing. Their interpretation is that administrative activity tends to use the public network intensively while manufacturing does not.

7.The increase in price sensitivity may arise from two complementary effects: Increases in infrastructure brings to the network users who are more price sensitive. Second, increases in infrastructure brings about higher volume uses of the network, making the demand more elastic overall. Both occur when the installation of digital infrastructure enables new services, or when modern infrastructure permits the transmission of data with greater speed and reliability, inducing higher volumes of traffic.

8. For reasons explained below, short of directly estimating demand functions, this assumption is needed to be able to estimate the aggregate effect of infrastructure deployment at the LEC level.

9. Comparing consumer surplus growth to last period's levels rather than first period's levels is a more conservative measure, particularly when infrastructure is growing rapidly.

10. Notice that this is not a profit calculation, as we have not considered installation costs.

11. As noted below in several footnotes, most of our inferences are robust to the assumption about the minor effect on operating expenses. Relaxing the assumption, however, unnecessarily complicates the exposition of the model and adds little additional insight.

12. Note that if operating expenses are reduced in proportion to investment then these additional savings will be equivalent to a lower per-unit cost of infrastructure, i.e., a lower W.

13. Notice that $\epsilon_{\mathrm{QP}}$, the negative of the elasticity of demand, must be positive by definition. Hence, $\theta$ must be greater than 1 in equilibrium.

14. Our estimation strategy for learning the degree of revenue enhancement due to infrastructure investment would be unaltered even if infrastructure lowers operating expenses. That is, if equation (3) were modified to include an additional term related to operating expenses, we would still end up with a basic relationship in the form found in (4).

15.If $P$ were functions of $I$, then we would not be able to perform the move from (4a) to ( $4 b$ ), and hence, $\gamma$ would not be identifiable from (4d).

16. We could only identify price elasticities from (4) under the strong restriction that $X_{L}$ is not an underlying determinant of political objectives, $\theta$, which seems implausible.

17.This restriction becomes difficult to satisfy with more complex specifications of the benefit function (e.g., such as translog or multiple inputs). 
18. Some infrastructure variables in a few LECs violate this assumption, particularly in the early years of the data. Thus, we add one unit of fiber to all LECs fiber levels.

19. We assume a firm that maximizes the present value of profits, while regulators are $a$ succession of individuals with a one period horizon. For analyses of the implications of multiperiod firms being regulated by single period regulators, see Lewis and Sappington (1991). See also Spiller and Urbiztondo (1994) for analyses of the endogeneity of regulators' horizons.

20. The complexity of the translog estimation, and the requirement to impose positive elasticities, would make such an extension extremely complex. As we found with this study's data, the additional complexity of the translog for a single input generated little additional insight.

21. Only companies that eam over $\$ 100$ million in revenue are required to report to the FCC.

22.GMS collected all forty eight state maps from the states' regulatory commissions and main telephone companies.

23.Although it is often the case that more than one carrier is operating in a county, over the entire state these discrepancies tend to average out, thus eliminating any major biases.

24. Though GTE and Contel merge during 1991, we continue to treat them as separate observations every year in our sample.

25. Fiber optic cable enables high volume traffic and is widely considered to be an essential part of the modern digital telephone system. Fiber optic cable is a high speed, high quality transmission mechanism that is limited in capacity only by the available terminal and repeater technology. It is purified silica glass using laser chips. Erbium-doped fiber amplifiers enhance the capacity to tens of thousands of gigabit-kilometers per second. Further digital technologies, deployed in conjunction with fiber, enable a variety of new services and more reliable as well as higher quality data services over phone lines. We measure the deployment fiber in "fiber-miles", which is the equivalent of a strand of fiber laid over one mile (For further discussion, see Kraashaur [1995]). In practice, many strands are laid over the same routes, so one thousand miles of fiber optic cable does not cover one thousand geographic miles. This should be thought of as a measure of the carrying capacity along communication lines. The typical patterns of deployment at an LEC occurred first between "feeder plants", i.e., between central office and a business or a remote terminal, where the volume of use is largest. Even as late as 1992, very little had yet been deployed directly to residences.

26. Integrated Services Digital Network, ISDN, involves installing lines and switches using a series of technical specifications designed to ease the movement of data traffic between two points over telephone lines. At its simple technical level ISDN is an international standard that allows voice, data, text, and video communications to travel simultaneously down the same transmission path. More practically, its use will be facilitated by the implementation of other 
digital technology and the adoption of SS7. It is an engineering concept that contemplates a public, end-to-end switched digital network in which time division switches and digital transmission paths accommodate multiple services originating at subscriber locations. While ISDN has been proposed for many years, its diffusion within the United States did not accelerate until the late 1980s and early 1990s. Even then, there were large differences across LECs due to widely-reported inter-company differences in efficiencies, regulatory-imposed rules on prices for installation and service, and regional differences in the demographics of local demand.

27. SS7 is a type of software for routing calls and data. It uses the existing backbone and switch network more efficiently, allowing greater use of the telephone network for data traffic. At a technical level, Signaling System 7 (SS7) is an CCITT standard for out-of-band signaling that conforms to ISDN standard specifications. More to the point, it is software that facilitates the use of ISDN, creating two channels within a single line. This improves the efficiency of a network because less capacity is tied up in the process of connecting a call.

28. The changes are due primarily to the treatment of revenue from cellular services.

29.This data field produces a slightly unbalanced panel among some small independent operators, but is complete for the RBOCs and for GTE.

30. Our other demographic data, while covering extremely diverse geographic/economic areas across the entire US, measure cross sectional differences with country-level averages, so we cannot easily construct this variable directly from BEA statistics.

31. In practice, this tends to primarily identify LECs that cover sprawling suburb-oriented sunbelt communities, which were the fastest growing areas in the 1980s.

32. DC also has a mayor, not a governor. Nebraska state politicians do not need to declare their political affiliations. These features make their political situation not easily comparable.

33. Due to the presence of independent regulators in a few regulatory agencies in a few years, a non-majority of democrats does not necessarily imply a majority of republicans. We tried standardizing on either party and found that it did not influence our inferences.

34. In this data set, this is about the most one can identify about political alignment. The alignment of govemor and legislature occurs virtually at the same time as alignment with the regulatory agency. Similarly, the alignment of the legislature and the regulator occurs virtually always with alignment with the govemor. For further discussion of these issues, see Greenstein, Sosa and Spiller [1996].

35. The range of estimates are computed over all years over the entire sample, including Washington DC and Nebraska. Since the amount of fiber grows over time, so too does the elasticity, but not greatly since the coefficient is so small. 
36. These are available for the authors on request. In general, only the coefficients on fiber yielded consistently positive infrastructure elasticities.

37. The high FIRE states include AZ, CA, CT, DE, FL, IL, MA, NJ and NY.

38. The sign on democratic governor is always negative and the coefficient on republican legislature is always lower than the coefficient on democratic legislature (and sometimes significant). Also, phone companies seem to be worse off when all the legislature and the governor are aligned instead of split (sometimes this is also significant).

39. In other words, we calculate $[f(I 2)-f(I 1)] /[f(I 2)]$, where $f($ is given to us by our elasticity estimates and $\mathrm{I} 1$ and $\mathrm{I} 2$ is given to us by actual investment by LECs at different time periods. Period one is either 1988 or 1989, depending on the sample, and period two is 1992.

40. This is partly because we can include Nebraska and Washington DC in the welfare calculations, but also because we do not need to exclude observations due to the absence of revenue data, as was necessary for the estimation.

41. For the same reasons described in the previous footnote.

42. If the elasticity of demand is constant, then the percentage of consumer surplus attributable to a recent decrease in price is $1-\left(\mathrm{P}_{1} / \mathrm{P}_{2}\right)^{(1-e)}$, which leads to the formula stated in the text.

43. Some of the simulations using 1.5 price elasticity stretch the realm of credibility since it is difficult to imagine that the elasticity of demand will stay constant for very large changes in prices.

44. This list includes everything in the category of $\mathrm{S}$. The results were not especially sensitive to the set of two-stage estimates we used. We did not use the estimates with LEC dummies because these dummies will also partly reflect political expectations.

45. As noted, both are excluded due to their unusual political institutions. It is interesting to note, however, that if we treat Nebraska as a "unified Republican legislature and governor" and compare it with other states, it generally rises to the near the top in our friendliness measure. This is consistent with perception that the state government goes to great lengths to encourage the telemarketing industry within the state.

46. Combining the estimates of $\gamma$ from (4d) with (7c) yields an equilibrium sensitivity of infrastructure to political friendliness (PF) as follows: $d\left(\log \left(I^{*}\right)\right) / d(P F)=P F /(1-\gamma)$, where $P F$ equals the estimates of $\delta^{3} \mathrm{~S}$ from equation (7c). For example, for $\gamma=0.1, \mathrm{~d}\left(\log \left(\mathrm{I}^{*}\right)\right) / \mathrm{d}(\mathrm{PF})=$ $1.1 \delta^{3} \mathrm{~S}$. For a political friendliness index of -0.25 , this derivative is -0.28 .

47. Note that in the M-L index, a lower number is friendlier, while in our index a higher number is friendlier. Hence, if they were to provide the same measure they would be negative conelated. 
48. We thank Edwin Dean and Henry Guyot of the BLS for tracking down these price series for us and bringing this to our attention. 
TABLE 1

DESCRIPTIVE STATISTICS ENDOGENOUS AND EXOGENOUS VARIABLES

\begin{tabular}{|c|c|c|c|c|c|c|}
\hline \multirow{2}{*}{ ENDOGENOUS VARIABLES } & MEAN & S. DEV & MIN & MAX & $\underline{\underline{\text { SUM }}}$ & N.OBS \\
\hline & & & & & & \\
\hline LOG ALL REVENUE & 12.75 & 1.42 & 7.35 & 15.86 & 5838.40 & 458 \\
\hline LOG LOCAL REVENUE & 11.88 & 1.64 & 6.09 & 15.16 & 3658.46 & 308 \\
\hline LOG (1+FIBER), FULL SMPL & 9.34 & 2.09 & 0.00 & 13.02 & 4276.78 & 458 \\
\hline LOG (1+FIBER), PARTIAL SMPL & 9.73 & 2.00 & 0.00 & 13.02 & 2996.11 & 308 \\
\hline $\operatorname{LOG}(1+\mathrm{ISDN})$ & 3.12 & 2.68 & 0.00 & 8.10 & 961.74 & 308 \\
\hline $\operatorname{LOG}(1+\mathrm{SS} 7)$ & 2.36 & 2.28 & 0.00 & 6.58 & 727.77 & 308 \\
\hline \multicolumn{7}{|l|}{ LOCAL DEMOGRAPHICS } \\
\hline FRAC URBANIZED & 0.46 & 0.28 & 0.00 & 0.94 & 208.95 & 458 \\
\hline FRAC RURAL & 0.37 & 0.20 & 0.02 & 0.86 & 167.71 & 458 \\
\hline LOG POPULATION & 7.02 & 1.40 & 2.81 & 10.17 & 3216.82 & 458 \\
\hline LOG PERCAPITA INCOME & 9.60 & 0.16 & 9.23 & 10.03 & 4395.92 & 458 \\
\hline SMALL (ST EMPLOYMENT $<10 \%$ & 0.27 & 0.44 & 0.00 & 1.00 & 124.00 & 458 \\
\hline LOG POPULATION DENS & 4.52 & 1.19 & 1.58 & 7.11 & 2072.00 & 458 \\
\hline LOG LAND AREA & 9.41 & 1.21 & 5.67 & 11.47 & 4308.57 & 458 \\
\hline CITY OF QUARTER MILLION & 0.39 & 0.49 & 0.00 & 1.00 & 180.00 & 458 \\
\hline CITY OF HALF MILLION & 0.19 & 0.39 & 0.00 & 1.00 & 85.00 & 458 \\
\hline FAST GROWING AREA & 0.16 & 0.37 & 0.00 & 1.00 & 75.00 & 458 \\
\hline LOG CONSTRUCTION WAGES & 2.33 & 0.15 & 2.06 & 2.69 & 1069.33 & 458 \\
\hline LOG CONSTRUCTION EMPLOY & 10.34 & 1.45 & 5.59 & 13.54 & 4736.92 & 458 \\
\hline CONSTRUCTION GROWTH & 0.21 & 9.83 & -31.41 & 101.99 & 94.48 & 458 \\
\hline LOG (1+FIBER) IN 1986 & 4.83 & 3.26 & 0.00 & 10.83 & 2213.22 & 458 \\
\hline INDEPENDENT & 0.18 & 0.38 & 0.00 & 1.00 & 73.00 & 458 \\
\hline GTE & 0.28 & 0.45 & 0.00 & 1.00 & 130.00 & 458 \\
\hline AMERITECH & 0.05 & 0.23 & 0.00 & 1.00 & 25.00 & 458 \\
\hline BELL ATLANTIC & 0.07 & 0.25 & 0.00 & 1.00 & 30.00 & 458 \\
\hline BELL SOUTH & 0.10 & 0.30 & 0.00 & 1.00 & 45.00 & 458 \\
\hline NYNEX & 0.07 & 0.25 & 0.00 & 1.00 & 30.00 & 458 \\
\hline PACIFIC BELL & 0.02 & 0.15 & 0.00 & 1.00 & 10.00 & 458 \\
\hline SOUTHWESTERN BELL & 0.05 & 0.23 & 0.00 & 1.00 & 25.00 & 458 \\
\hline USWEST & 0.14 & 0.35 & 0.00 & 1.00 & 65.00 & 458 \\
\hline \multicolumn{7}{|l|}{ STATE DEMOGRAPHICS } \\
\hline STATE GNP GROWTH & 1.33 & 2.30 & -7.77 & 9.62 & 611.15 & 458 \\
\hline LOG STATE/LOC PCAPINC & 0.04 & 0.10 & -0.16 & 0.40 & 16.80 & 458 \\
\hline FRAC ST GNP N FIRE & 0.07 & 0.01 & 0.05 & 0.12 & 32.63 & 458 \\
\hline \multicolumn{7}{|l|}{ POLITICAL VARIABLES } \\
\hline COMMISSION NOT ELECT & 0.69 & 0.46 & 0.00 & 1.00 & 315.00 & 458 \\
\hline DEMOCRAT COMM MAJORITY & 0.65 & 0.48 & 0.00 & 1.00 & 299.00 & 458 \\
\hline NOT EL \& DEM COMM MAJ & 0.42 & 0.49 & 0.00 & 1.00 & 193.00 & 458 \\
\hline STATE VOTE DUKAKIS & 0.45 & 0.05 & 0.34 & 0.56 & 207.63 & 458 \\
\hline GOVERNOR DEMOCRAT & 0.54 & 0.50 & 0.00 & 1.00 & 248.00 & 458 \\
\hline REPUBLICAN LEGISTLATURE & 0.10 & 0.31 & 0.00 & 1.00 & 48.00 & 458 \\
\hline DEMOCRAT LEGISTLATURE & 0.63 & 0.48 & 0.00 & 1.00 & 290.00 & 458 \\
\hline ALIGN REG, GOV & 0.80 & 0.40 & 0.00 & 1.00 & 368.00 & 458 \\
\hline ALIGN REG, GOV AND LEGIST & 0.29 & 0.45 & 0.00 & 1.00 & 131.00 & 458 \\
\hline
\end{tabular}


TABLE 2

FULL SAMPLE, 458 OBSERVATIONS, 1988-1992

FIBER ONLY

TWO STAGE LEAST SQUARES

REVENUE EQUATION

\begin{tabular}{|c|c|c|c|c|c|c|c|c|c|c|}
\hline \multirow[t]{2}{*}{$\begin{array}{l}\text { TYPE OF REVENUE } \\
\text { SPECIFICATION }\end{array}$} & \multicolumn{3}{|c|}{$\begin{array}{l}\text { ALL } \\
\text { NO LEC DUMMIES }\end{array}$} & \multicolumn{3}{|c|}{$\begin{array}{l}\text { LOCAL } \\
\text { NO LEC DUMMIES }\end{array}$} & \multicolumn{2}{|c|}{$\begin{array}{l}\text { ALL } \\
\text { W/LEC DUMMIES }\end{array}$} & \multicolumn{2}{|c|}{\begin{tabular}{|l} 
LOCAL \\
W/ LEC DUMMIES
\end{tabular}} \\
\hline & $\underline{\text { EST }}$ & $\underline{\text { S.ERR }}$ & $\underline{\mathbf{T}}$ & EST & $\underline{\underline{S E R R}}$ & $\underline{\mathbf{T}}$ & $\underline{\text { EST }}$ & $\underline{S . E R R} \underline{\mathrm{T}}$ & $\underline{\text { EST }}$ & $\underline{S . E R R} \quad \underline{\mathrm{T}}$ \\
\hline GAMMA ON FIBER & 0.06 & 0.04 & & 0.09 & 0.04 & $* *$ & 0.10 & $0.05^{* *}$ & 0.11 & $0.06^{* *}$ \\
\hline POLITICAL VARIABLES & & & & & & & & & & \\
\hline COMMISSION NOT ELECT & 0.37 & 0.09 & ** & 0.52 & 0.10 & $* *$ & 0.37 & $0.10^{* *}$ & 0.52 & $0.11 * *$ \\
\hline DEM COMMISH MAJORITY & 0.30 & 0.11 & ** & 0.51 & 0.12 & $* *$ & 0.28 & $0.11^{* *}$ & 0.47 & $0.13^{*} *$ \\
\hline NOT EL \& DEM COMM MAJ & -0.33 & 0.11 & $* *$ & -0.50 & 0.12 & $* *$ & -0.34 & $0.11^{* *}$ & -0.49 & $0.12 * *$ \\
\hline STATE VOTE DUKAKIS & -2.10 & 0.54 & ** & -2.10 & 0.59 & $* *$ & -1.15 & 0.86 & -0.82 & 0.95 \\
\hline GOVERNOR DEMOCRAT & -0.07 & 0.07 & & -0.11 & 0.08 & & -0.09 & 0.09 & -0.11 & 0.09 \\
\hline ALL LEG DEM & 0.08 & 0.07 & & 0.10 & 0.08 & & -0.05 & 0.12 & -0.04 & 0.13 \\
\hline ALL LEG REP & -0.10 & 0.10 & & -0.12 & 0.11 & & 0.04 & 0.20 & 0.09 & 0.22 \\
\hline ALIGN REG, GOV, LEG & -0.12 & 0.07 & & -0.07 & 0.08 & & -0.07 & 0.10 & -0.03 & 0.11 \\
\hline ALIGN REG, GOV & 0.06 & 0.07 & & 0.08 & 0.08 & & 0.03 & 0.08 & 0.04 & 0.08 \\
\hline STATE DEMOGRAPHICS & & & & & & & & & & \\
\hline STATE GNP GROWTH & 0.00 & 0.01 & & 0.00 & 0.01 & & 0.01 & 0.01 & 0.01 & 0.01 \\
\hline LOG STATE/LOC PCAPINC & -2.23 & 0.47 & ** & -3.32 & 0.51 & $* *$ & -1.77 & $0.56^{* *}$ & -2.21 & $0.61 * *$ \\
\hline FRAC ST GNP IN FIRE & 10.52 & 2.84 & ** & 14.15 & 3.10 & $* *$ & 7.69 & $3.10^{* *}$ & 10.63 & $3.41^{* *}$ \\
\hline LOCAL DEMOGRAPHICS & & & & & & & & & 7 & \\
\hline FRAC URBANIZED & 1.07 & 0.25 & $* *$ & 1.39 & 0.28 & $* *$ & 1.17 & $0.27 * *$ & 1.45 & $0.30 * *$ \\
\hline FRAC RURAL & 1.77 & 0.30 & $* *$ & 2.07 & 0.33 & $* *$ & 1.57 & $0.31 * *$ & 1.83 & $0.34^{* *}$ \\
\hline LOG POPULATION & 0.71 & 0.05 & ** & 0.67 & 0.06 & $* *$ & 0.68 & $0.06 * *$ & 0.64 & $0.07 * *$ \\
\hline LOG PERCAPITA INCOME & 0.12 & 0.30 & & -0.47 & 0.32 & & -0.24 & 0.35 & -0.83 & $0.38 * *$ \\
\hline LOG POPULATION DENS & -0.09 & 0.03 & ** & -0.07 & 0.04 & & -0.09 & $0.04^{* *}$ & -0.03 & 0.05 \\
\hline SMALL (ST EMP < 10\%) & 0.20 & 0.08 & $* *$ & 0.15 & 0.08 & $*$ & 0.17 & $0.08 * *$ & 0.12 & 0.09 \\
\hline DUMMY 89 & -0.06 & 0.07 & & -0.04 & 0.08 & & -0.06 & 0.07 & -0.02 & 0.08 \\
\hline DUMMY 90 & -0.11 & 0.08 & & -0.05 & 0.09 & & -0.11 & 0.08 & -0.03 & 0.09 \\
\hline DUMMY 91 & -0.17 & 0.09 & $*$ & -0.09 & 0.10 & & -0.17 & $0.10^{*}$ & -0.06 & 0.11 \\
\hline DUMMY 92 & -0.19 & 0.09 & $* *$ & -0.07 & 0.10 & & -0.24 & $0.10^{* *}$ & -0.08 & 0.11 \\
\hline CITY OF QUART MILLION & 0.48 & 0.07 & $* *$ & 0.60 & 0.07 & $* *$ & 0.51 & $0.07^{* *}$ & 0.60 & $0.08 * *$ \\
\hline CITY OF HALF MILLION & 0.22 & 0.07 & $* *$ & 0.33 & 0.08 & $* *$ & 0.32 & $0.08 * *$ & 0.39 & $0.09 * *$ \\
\hline FAST GROWER & -0.10 & 0.08 & & -0.27 & 0.08 & $* *$ & -0.11 & 0.09 & -0.24 & $0.10^{* *}$ \\
\hline CONSTANT, REV EQ & 5.07 & 2.66 & & 8.91 & 2.90 & $* *$ & 8.23 & $3.09 * *$ & 1.74 & $3.40^{* *}$ \\
\hline GTE & & & & & & & 0.00 & 0.12 & 0.13 & 0.14 \\
\hline INDEPENDENTS & & & & & & & 0.24 & $0.13 *$ & 0.41 & $0.15 * *$ \\
\hline AMERITECH & & & & & & & -0.30 & 0.19 & -0.02 & 0.20 \\
\hline BELL ATLANTIC & & & & & & & 0.05 & 0.16 & 0.27 & 0.18 \\
\hline BELL SOUTH & & & & & & & 0.05 & 0.17 & 0.41 & $0.19 * *$ \\
\hline NYNEX & & & & & & & 0.18 & 0.16 & 0.45 & $0.18 * *$ \\
\hline PACIFIC BELL & & & & & & & 0.05 & 0.21 & 0.50 & $0.23 * *$ \\
\hline SOUTHWESTERN BELL & & & & & & & 0.05 & 0.17 & 0.45 & $0.19 * *$ \\
\hline USWEST & & & & & & & -0.10 & 0.18 & 0.20 & 0.19 \\
\hline
\end{tabular}


TABLE 3

PARTIAL SAMPLE, 309 OBSERVATIONS, 1989-1992

FIBER, ISDN, SS7

TWO STAGE LEAST SOUARES

REVENUE EQUATION

\begin{tabular}{|c|c|c|c|c|c|c|c|c|}
\hline \multirow{2}{*}{$\begin{array}{l}\text { TYPE OF REVENUE } \\
\text { SPECIFICATION }\end{array}$} & \multicolumn{2}{|c|}{$\begin{array}{l}\text { ALL } \\
\text { NO LEC DUMMIES }\end{array}$} & \multicolumn{2}{|c|}{$\begin{array}{l}\text { LOCAL } \\
\text { NO LEC DUMMIES }\end{array}$} & \multicolumn{2}{|c|}{$\begin{array}{l}\text { ALL } \\
\text { W/LEC DUMMIES }\end{array}$} & \multicolumn{2}{|c|}{$\begin{array}{l}\text { LOCAL } \\
\text { W/ LEC DUMMIES }\end{array}$} \\
\hline & EST & $\underline{\underline{S E R R}} \underline{\underline{T}}$ & $\underline{\text { EST }}$ & $\underline{S . E R R} \quad \underline{T}$ & $\underline{\text { EST }}$ & $\underline{S . E R R} \underline{\mathrm{T}}$ & $\underline{\text { EST }}$ & $\underline{S E R R} \underline{T}$ \\
\hline GAMMA ON FIBER & 0.08 & $0.04^{*}$ & 0.08 & $0.05 *$ & 0.16 & $0.06^{* *}$ & 0.18 & $0.06^{* *}$ \\
\hline GAMMA ON ISDN & 0.00 & 0.04 & 0.03 & 0.04 & 0.16 & $0.06 * *$ & 0.13 & $0.07 * *$ \\
\hline GAMMA ON SS7 & -0.01 & 0.05 & -0.04 & 0.05 & -0.03 & 0.10 & 0.01 & 0.10 \\
\hline POLITICAL VARIABLES & & & & & & & & \\
\hline COMMISSION NOT ELECT & 0.41 & $0.12^{* *}$ & 0.54 & $0.13 * *$ & 0.40 & $0.12 * *$ & 0.52 & $0.12 * *$ \\
\hline DEM COMMISH MAJORITY & 0.49 & $0.13^{* *}$ & 0.68 & $0.14^{* *}$ & 0.52 & $0.13^{* *}$ & 0.69 & $0.14^{* *}$ \\
\hline NOT EL \& DEM COMM MAJ & -0.39 & $0.13^{* *}$ & -0.51 & $0.14 * *$ & -0.43 & $0.14^{* *}$ & -0.49 & $0.14 *$ \\
\hline STATE VOTE DUKAKIS & -2.16 & $0.68^{* *}$ & -2.38 & $0.74 * *$ & -2.61 & $1.05 * *$ & -2.22 & $1.09 *$ \\
\hline GOVERNOR DEMOCRAT & -0.03 & 0.08 & -0.04 & 0.09 & -0.04 & 0.09 & -0.06 & 0.10 \\
\hline ALL L & -0.01 & 0.08 & 0.03 & 0.09 & -0.05 & 0.13 & -0.02 & 0.14 \\
\hline ALL LEG REP & -0.11 & 0.10 & -0.14 & 0.11 & -0.30 & $0.2 I$ & -0.26 & 0.22 \\
\hline ALIGN & -0.12 & 0.09 & -0.09 & 0.09 & -0.17 & 0.11 & -0.09 & 0.12 \\
\hline ALIGN & 0.00 & 0.08 & -0.02 & 0.09 & 0.12 & 0.09 & 0.08 & 0.09 \\
\hline RAPHICS & & & & & & & & \\
\hline STATE & -0.01 & 0.01 & -0.01 & 0.02 & 0.01 & 0.02 & 0.01 & 0.02 \\
\hline APINC & -2.79 & $0.61^{* *}$ & -4.33 & $0.66 * *$ & -2.28 & $0.68 * *$ & -3.32 & $0.70^{*}$ \\
\hline FRAC S & 3.06 & 3.60 & 7.21 & $3.88 *$ & 3.61 & 4.18 & 9.28 & $4.32 *$ \\
\hline LOCAI & & & & & & & & \\
\hline $\mathrm{RAC}$ & 1.26 & $0.31^{* *}$ & 1.29 & $0.34 * *$ & 1.49 & $0.38 * *$ & 1.71 & $0.39 *$ \\
\hline FRAC & 1.42 & $0.36 * *$ & 1.63 & $0.38 * *$ & 1.75 & $0.48 * *$ & 1.92 & $0.49 * *$ \\
\hline LOG F & 0.86 & $0.07^{* *}$ & 0.89 & $0.08^{* *}$ & 0.78 & $0.09 * *$ & 0.77 & $0.10^{* *}$ \\
\hline LOG $P$ & 0.24 & 0.39 & -0.19 & 0.42 & 0.04 & $0.5 !$ & -0.58 & 0.53 \\
\hline LOG PC & -0.09 & $0.04 * *$ & -0.06 & 0.04 & -0.18 & $0.05 * *$ & -0.13 & $0.05^{* *}$ \\
\hline$\Gamma \mathrm{EMP}<10 \%)$ & 0.61 & $0.11^{* *}$ & 0.65 & $0.12^{* *}$ & 0.54 & $0.12 * *$ & 0.59 & $0.12 *$ \\
\hline DUMN & -0.05 & 0.07 & 0.00 & 0.08 & -0.20 & $0.10 * *$ & -0.16 & 0.11 \\
\hline DUM & -0.12 & 0.09 & -0.06 & 0.09 & -0.34 & $0.15^{* *}$ & -0.30 & $0.16 *$ \\
\hline DUMN & -0.13 & 0.16 & 0.04 & 0.18 & -0.51 & 0.32 & -0.47 & 0.33 \\
\hline CITY & 0.18 & $0.10^{*}$ & 0.18 & $0.10^{*}$ & 0.07 & 0.12 & 0.06 & 0.13 \\
\hline MILLION & -0.02 & 0.08 & 0.05 & 0.09 & 0.06 & 0.10 & 0.06 & 0.10 \\
\hline FAST & -0.07 & 0.08 & -0.21 & $0.09 * *$ & -0.24 & $0.11^{* *}$ & -0.39 & $0.12 *$ \\
\hline CONSTANT, REV EQ & 0.34 & 3.59 & 5.57 & 3.87 & 0.27 & 4.80 & 8.85 & $4.96 *$ \\
\hline GTE & & & & & 0.12 & 0.13 & 0.29 & $0.14^{* *}$ \\
\hline INDEPENDENTS & & & & & 0.90 & $0.31^{* *}$ & 1.04 & $0.32 *$ \\
\hline AMERITECH & & & & & -0.54 & $0.26 * *$ & -0.14 & 0.27 \\
\hline BELL ATLANTIC & & & & & -0.54 & $0.30^{*}$ & -0.33 & 0.31 \\
\hline BELL SOUTH & & & & & -0.42 & $0.23 *$ & -0.03 & 0.24 \\
\hline NYNEX & & & & & 0.00 & 0.21 & 0.31 & 0.22 \\
\hline PACIFIC BELL & & & & & -0.40 & $0.24 *$ & 0.03 & 0.25 \\
\hline WESTERN BELL & & & & & -0.22 & 0.23 & 0.23 & 0.24 \\
\hline USWEST & & & & & -0.49 & $0.25 *$ & -0.12 & 0.26 \\
\hline
\end{tabular}


TABLE 4

\section{POINT ESTIMATES OF INFRASTRUCTURE ELASTICITIES TWO STAGE LEAST SQUARES ESTIMATES}

COBB-DOUGLASS

\begin{tabular}{|l|l|lll|}
\hline NO LEC DUMMIES & FIBER ISDN & SS7 \\
\hline FIBER ONLY, FULL SAMPLE & ALL REVENUE & 0.06 & & \\
& LOCAL REVENUE & 0.09 & & \\
FIBER, ISDN, SS7, PARTIAL SAMPLE & ALL REVENUE & 0.08 & 0.00 & -0.01 \\
& LOCAL REVENUE & 0.08 & 0.03 & -0.04 \\
\hline W/LEC DUMMIES & ALL REVENUE & 0.10 & & \\
\hline FIBER ONLY, FULL SAMPLE & LOCAL REVENUE & 0.11 & & \\
FIBER, ISDN, SS7, PARTIAL SAMPLE & ALL REVENUE & 0.16 & 0.16 & -0.03 \\
& LOCAL REVENUE & 0.18 & 0.13 & 0.01 \\
\hline
\end{tabular}

TRANSLOG

NO LEC DUMMIES FIBER

FIBER ONLY, FULL SAMPLE

ALL REVENUE

MEAN VALUE

0.06

ST. DEVIATION

0.01

MIN

MAX

0.02

0.07

FIBER ONLY, FULL SAMPLE

LOCAL REVENUE
MEAN VALUE

ST. DEVIATION

0.02

MIN

0.01

MAX

0.11 
TABLE 5

ESTIMATED GAINS FROM INFRASTRUCTURE

\begin{tabular}{|l|ccc|}
\hline & MEAN & \multicolumn{3}{l|}{ ST. DEV MEDIAN } \\
\hline FIBER: GAMMA $=0.07$ & & & \\
PERCENT DUE TO INFRASTRUCTURE & 0.10 & 0.08 & 0.09 \\
& & & \\
EQUIVALENT \% PRICE DECLINE, $\mathrm{e}=2.0$ & 0.12 & 0.12 & 0.10 \\
EQUIVALENT \% PRICE DECLINE, $\mathrm{e}=2.5$ & 0.08 & 0.07 & 0.06 \\
\hline & & & \\
\hline FIBER, ISDN: GAMMA $=\{0.11,0.02\}$ & & & \\
& & & \\
PERCENT DUE TO INFRASTRUCTURE & 0.13 & 0.08 & 0.13 \\
& & & \\
EQUIVALENT \% PRICE DECLINE, e $=2.0$ & 0.16 & 0.08 & 0.15 \\
EQUIVALENT \% PRICE DECLINE, e $=2.5$ & 0.10 & 0.05 & 0.10 \\
\hline
\end{tabular}


TABLE 6

\section{MARGINAL REVENUE OF A FIBER MILE REGIONAL BELL OPERATING COMPANIES 1988-1992}

\begin{tabular}{|c|c|c|c|c|c|}
\hline & 1988 & 1989 & 1990 & 1991 & 1992 \\
\hline \multicolumn{6}{|l|}{ GAMMA $=0.7$} \\
\hline AVERAGE & 9376.9 & 2358.6 & 1546.4 & 1032.9 & 706.4 \\
\hline STANDARD DEVIATION & 31133.4 & 1371.3 & 700.3 & 412.9 & 344.9 \\
\hline FIRST QUARTILE & 2051.1 & 1578.9 & 1067.5 & 768.8 & 472.7 \\
\hline MEDIAN & 2762.6 & 2032.4 & 1370.4 & 930.9 & 662.0 \\
\hline THIRD QUARTILE & 3885.5 & 2581.8 & 1775.9 & 1227.3 & 835.9 \\
\hline \multicolumn{6}{|l|}{ GAMMA $=0.11$} \\
\hline AVERAGE & 14735.1 & 3706.3 & 2430.1 & 1623.1 & 1110.1 \\
\hline STANDARD DEVIATION & 48923.9 & 2154.9 & 1100.5 & 648.9 & 542.1 \\
\hline FIRST QUARTILE & 3223.1 & 2481.1 & 1677.5 & 1208.0 & 742.7 \\
\hline MEDIAN & 4341.3 & 3193.7 & 2153.5 & 1462.8 & 1040.3 \\
\hline THIRD QUARTILE & 6105.7 & 4057.1 & 2790.6 & 1928.6 & 1313.6 \\
\hline \multicolumn{6}{|l|}{ GAMMA $=0.14$} \\
\hline AVERAGE & 18753.7 & 4717.1 & 3092.8 & 2065.8 & 1412.8 \\
\hline STANDARD DEVIATION & 62266.7 & 2742.6 & 1400.6 & 825.8 & 689.9 \\
\hline FIRST QUARTILE & 4102.2 & 3157.8 & 2135.0 & 1537.5 & 945.3 \\
\hline MEDIAN & 5525.3 & 4064.7 & 2740.8 & 1861.8 & 1324.0 \\
\hline THIRD QUARTILE & 7770.9 & 5163.5 & 3551.7 & 2454.6 & 1671.8 \\
\hline \multicolumn{6}{|c|}{ TRANSLOG, MEAN(GAMMA) $=0.06$} \\
\hline AVERAGE & 7011.7 & 2079.8 & 1409.4 & 968.2 & 687.6 \\
\hline STANDARD DEVIATION & 20803.5 & 1003.3 & 550.6 & 366.6 & 298.5 \\
\hline F́IRST QUARTILE & 1922.8 & 1446.7 & 1011.2 & 744.1 & 489.1 \\
\hline MEDIAN & 2466.4 & 1816.3 & 1340.6 & 913.9 & 650.1 \\
\hline THIRD QUARTILE & 3187.8 & 2428.6 & 1615.8 & 1064.4 & 786.7 \\
\hline
\end{tabular}


TABLE 7

THE POLITICAL FRIENDLINESS OF STATE REGULATORS, 1988-1992

\begin{tabular}{|c|c|c|c|c|c|c|}
\hline STATE & INDEX1988 & RANK IN 88 & M-L INDEX & INDEX1992 F & RANK IN 92 & M-L INDEX \\
\hline$\overline{A L A B A M A}$ & -0.07 & 6 & 7 & -0.16 & 7 & 5 \\
\hline ARIZONA & -0.18 & 19 & 10 & -0.17 & 9 & 9 \\
\hline ARKANSAS & -0.26 & 31 & 11 & -0.35 & 31 & 10 \\
\hline CALIFORNIA & -0.08 & 7 & 7 & -0.17 & 8 & 5 \\
\hline COLORADO & -0.31 & 38 & 9 & -0.40 & 39 & 8 \\
\hline CONNECTICUT & -0.30 & 37 & 6 & -0.31 & 27 & 5 \\
\hline DELAWARE & -0.04 & 3 & 6 & -0.14 & 5 & 6 \\
\hline FLORIDA & 0.00 & 1 & 5 & -0.22 & 16 & 3 \\
\hline GEORGIA & -0.19 & 21 & 9 & -0.28 & 24 & 7 \\
\hline IDAHO & -0.14 & 13 & 11 & -0.13 & 4 & 7 \\
\hline ILLINOIS & -0.08 & 8 & 7 & -0.17 & 12 & 13 \\
\hline INDIANA & -0.20 & 23 & 7 & -0.17 & 11 & 5 \\
\hline IOWA & -0.18 & 20 & 10 & -0.28 & 23 & 7 \\
\hline KANSAS & -0.28 & 33 & 11 & -0.25 & 20 & 8 \\
\hline KENTUCKY & -0.23 & 29 & 6 & -0.32 & 30 & 6 \\
\hline LOUISIANA & -0.29 & 36 & 14 & -0.39 & 37 & 13 \\
\hline MAINE & -0.11 & 12 & 7 & -0.09 & 2 & 7 \\
\hline MARYLAND & -0.32 & 39 & 10 & -0.41 & 40 & 6 \\
\hline MASSACHUSETTS & -0.40 & 45 & 9 & -0.25 & 21 & 6 \\
\hline MICHIGAN & -0.20 & 22 & 8 & -0.18 & 13 & 10 \\
\hline MINNESOTA & -0.39 & 44 & 4 & -0.24 & 17 & 7 \\
\hline MISSISSIPPI & -0.15 & 14 & 13 & 0.00 & 1 & 7 \\
\hline MISSOURI & -0.48 & 47 & 8 & -0.57 & 46 & 8 \\
\hline MONTANA & -0.27 & 32 & 13 & -0.30 & 26 & 12 \\
\hline NEVADA & -0.10 & 11 & 8 & -0.19 & 14 & 8 \\
\hline NEW HAMPSHIRE & -0.15 & 15 & 13 & -0.24 & 18 & 7 \\
\hline NEW JERSEY & -0.46 & 46 & 7 & -0.38 & 35 & 7 \\
\hline NEW MEXICO & -0.23 & 28 & 9 & -0.39 & 38 & 8 \\
\hline NEW YORK & -0.34 & 41 & 11 & -0.43 & 41 & 8 \\
\hline NORTH CAROLINA & -0.09 & 9 & 4 & -0.46 & 43 & 4 \\
\hline NORTH DAKOTA & -0.20 & 25 & 9 & -0.29 & 25 & 9 \\
\hline OHIO & -0.17 & 18 & 9 & -0.15 & 6 & 10 \\
\hline OKLAHOMA & -0.10 & 10 & 7 & -0.62 & 47 & 10 \\
\hline OREGON & -0.36 & 43 & 9 & -0.38 & 36 & 6 \\
\hline PENNSYLVANIA & -0.28 & 34 & 8 & -0.37 & 33 & 9 \\
\hline RHODE ISLAND & -0.20 & 24 & 10 & -0.53 & 45 & 10 \\
\hline SOUTH CAROLINA & -0.03 & 2 & 7 & -0.12 & 3 & 5 \\
\hline SOUTH DAKOTA & -0.35 & 42 & 9 & -0.44 & 42 & 9 \\
\hline TENNESSEE & -0.23 & 27 & 10 & -0.32 & 29 & 8 \\
\hline TEXAS & -0.06 & 5 & 7 & -0.31 & 28 & 9 \\
\hline UTAH & -0.06 & 4 & 7 & -0.17 & 10 & 8 \\
\hline VERMONT & -0.29 & 35 & 5 & -0.38 & 34 & 7 \\
\hline VIRGINIA & -0.15 & 16 & 7 & -0.24 & 19 & 5 \\
\hline WASHINGTON & -0.34 & 40 & 7 & -0.36 & 32 & 6 \\
\hline WEST VIRGINIA & -0.22 & 26 & 11 & -0.47 & 44 & 11 \\
\hline WISCONSIN & -0.23 & 30 & 4 & -0.21 & I5 & 1 \\
\hline WYOMING & -0.17 & 17 & 13 & -0.26 & 22 & 9 \\
\hline
\end{tabular}


TABLE 8

COMPARISON OF ESTIMATED COST INDICES

APPENDIX 2 APPENDLX 3 APPENDIX 3

\begin{tabular}{|c|c|c|c|c|c|c|}
\hline INPUT & FIBER & \multicolumn{3}{|c|}{ FIBER } & \multicolumn{2}{|l|}{ ISDN } \\
\hline REVENUE & ALL & LOCAL & ALL & LOCAL & ALL & LOCAL \\
\hline CONTEL & 1.00 & 1.00 & 1.00 & 1.00 & 1.00 & 1.00 \\
\hline GTE & 1.37 & 1.58 & 1.42 & 1.61 & 0.61 & 0.65 \\
\hline INDEPENDENT & 2.13 & 2.39 & 3.18 & 3.49 & 0.66 & 0.63 \\
\hline AMERITECH & 0.92 & 1.45 & 0.69 & 1.10 & 0.08 & 0.12 \\
\hline BELL ATLANTIC & 0.62 & 0.86 & 0.44 & 0.64 & 0.03 & 0.04 \\
\hline BELL SOUTH & 1.14 & 1.75 & 0.63 & 0.99 & 0.16 & 0.23 \\
\hline NYNEX & 0.58 & 0.76 & 0.50 & 0.67 & 0.22 & 0.26 \\
\hline PACIFIC BELL & 0.47 & 0.61 & 0.43 & 0.62 & 0.15 & 0.19 \\
\hline SOUTHWESTERN BELL & 0.90 & 1.31 & 0.66 & 0.96 & 0.15 & 0.20 \\
\hline USWEST & 0.72 & 1.09 & 0.45 & 0.68 & 0.06 & 0.08 \\
\hline 1988 & 1.00 & & & & & \\
\hline 1989 & 0.55 & & 1.00 & & 1.00 & \\
\hline 1990 & 0.35 & & 0.67 & & 0.39 & \\
\hline 1991 & 0.27 & & 0.48 & & 0.21 & \\
\hline 1992 & 0.19 & & 0.35 & & 0.13 & \\
\hline
\end{tabular}




\section{APPENDIX 1}

FULL SAMPLE, 458 OBSERVATIONS, 1988-1992

FIBER ONLY

TWO AND THREE STAGE LEAST SQUARES

COBB-DOUGLAS. TRANSLOG SPECIFICATION

REVENUE EQUATION

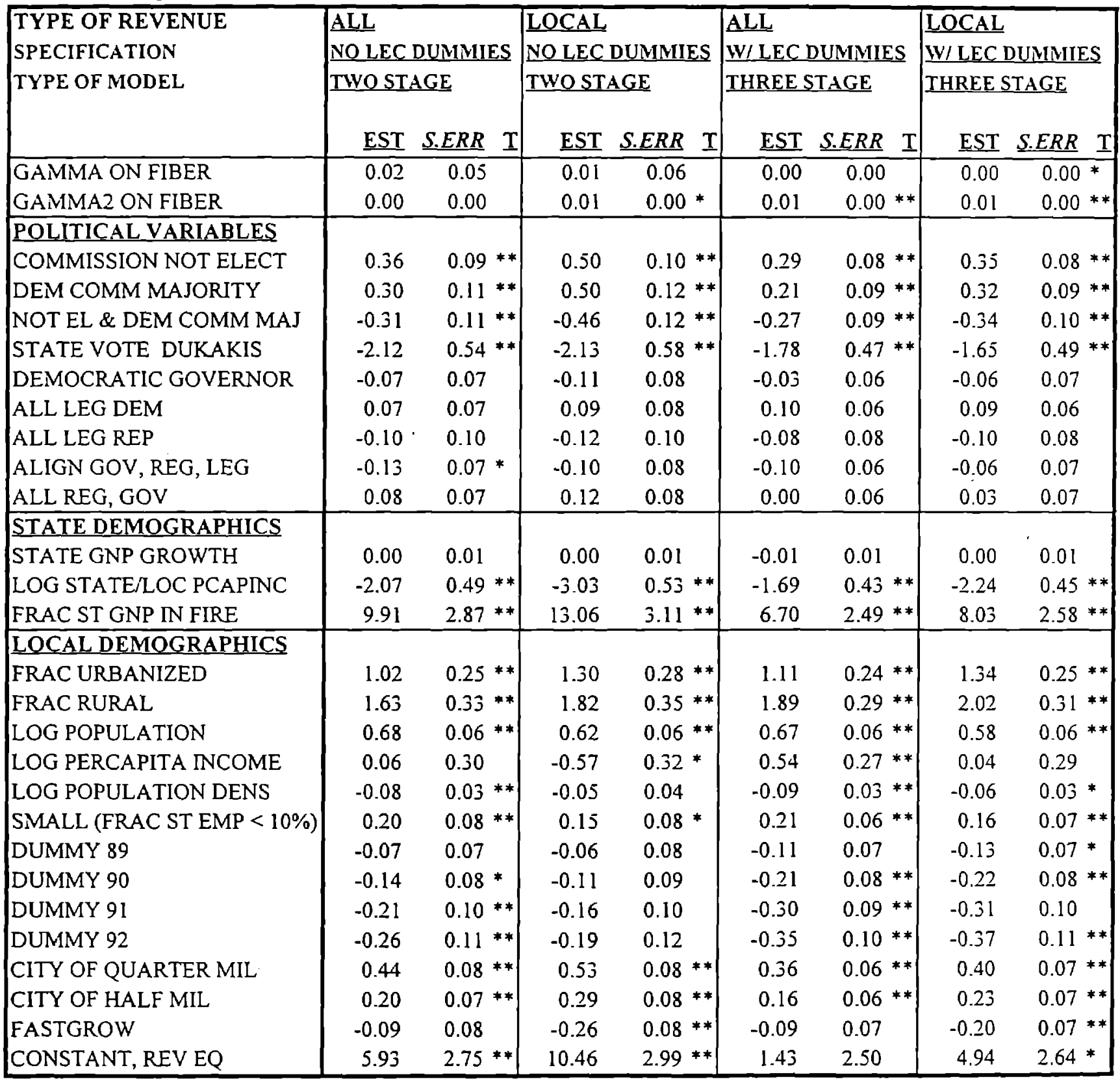


FULL SAMPLE, 458 OBSERVATIONS, 1988-1992

FIBER ONLY

TWO AND THREE STAGE LEAST SOUARES

COBB-DOUGLAS.TRANSLOG SPECIFICATION

COST EQUATION, FIBER

\begin{tabular}{|c|c|c|c|c|c|c|}
\hline $\begin{array}{l}\text { TYPE OF REVENUE } \\
\text { SPECIFICATION } \\
\text { TYPE OF MODEL }\end{array}$ & $\begin{array}{l}\text { ALL } \\
\text { NO LEC DUMIMIES } \\
\text { TVOO STAGE }\end{array}$ & $\begin{array}{l}\text { LOCAL } \\
\text { NO LEC DUMMIES } \\
\text { TWOSTAGE }\end{array}$ & $\begin{array}{r}\text { ALL } \\
\text { W/LEC } \\
\text { THREE } \\
\text { EST } \\
\end{array}$ & $\begin{array}{l}\text { UUMIES } \\
\text { TAGE } \\
\text { S.ERR I }\end{array}$ & \begin{tabular}{|} 
LOCAL \\
W/ LEC \\
THREE \\
EST \\
\end{tabular} & $\begin{array}{l}\text { DUMIMIES } \\
\text { STAGE } \\
\text { S.ERR T }\end{array}$ \\
\hline CONSTANT, COST EQ & & & -1.13 & 1.51 & -0.38 & 1.52 \\
\hline LOG CONSTRUCT WAGES & & & 0.65 & $0.24^{* *}$ & 0.45 & $0.24 *$ \\
\hline LOG CONSTRUCT EMPLOY & & & 0.16 & 0.14 & 0.16 & 0.14 \\
\hline CONSTRUCTION GROWTH & & & 0.00 & 0.00 & 0.00 & 0.00 \\
\hline LOG POPULATION & & & -0.16 & 0.28 & -0.18 & 0.29 \\
\hline LOG POPULATION SQ & & & 0.01 & 0.03 & 0.01 & 0.03 \\
\hline LOG LAND AREA & & & -0.02 & 0.30 & -0.21 & 0.31 \\
\hline LOG LAND AREA SQ & & & 0.01 & 0.02 & 0.01 & 0.02 \\
\hline LOG LAND AND LOG POP & & & -0.01 & 0.03 & 0.01 & 0.03 \\
\hline CONTEL & & & 0.22 & $0.14 *$ & 0.30 & $0.14 * *$ \\
\hline GTE & & & 0.61 & $0.14^{* *}$ & 0.63 & $0.14^{* *}$ \\
\hline AMERITECH & & & 0.20 & 0.18 & 0.52 & $0.18^{* *}$ \\
\hline BELL ATLANTIC & & & -0.21 & 0.17 & 0.05 & 0.17 \\
\hline BELL SOUTH & & & 0.15 & 0.18 & 0.42 & $0.18 * *$ \\
\hline NYNEX & & & -0.32 & $0.16^{* *}$ & -0.11 & 0.17 \\
\hline PACIFIC BELL & & & 0.04 & 0.24 & 0.21 & 0.25 \\
\hline SOUTHWESTERN BELL & & & -0.17 & 0.18 & 0.09 & 0.18 \\
\hline USWEST & & & -0.15 & 0.16 & 0.14 & 0.17 \\
\hline LOG (1+FIBER) IN 1986 & & & -0.05 & $0.01 * *$ & -0.05 & $0.02 * *$ \\
\hline DUMMY 89 & & & -0.38 & $0.09 * *$ & -0.36 & $0.09 * *$ \\
\hline DUMMY 90 & & & -0.77 & $0.09 * *$ & -0.72 & $0.09 * *$ \\
\hline DUMMY 91 & & & -1.03 & $0.09 * *$ & -0.95 & $0.10^{* *}$ \\
\hline DUMMY 92 & & & -1.36 & $0.09 * *$ & -1.25 & $0.09 * *$ \\
\hline
\end{tabular}


FULL SAMPLE, 458 OBSERVATIONS, 1988-1992

FIBER ONLY

THREE STAGE LEAST SQUARES

REVENUE EOUATION

\begin{tabular}{|c|c|c|c|c|c|c|c|c|}
\hline \multirow[t]{2}{*}{$\begin{array}{l}\text { TYPE OF REVENUE } \\
\text { SPECIFICATION }\end{array}$} & \multicolumn{2}{|c|}{$\begin{array}{l}\text { ALL } \\
\text { NO LEC DUMMIES }\end{array}$} & \multicolumn{2}{|c|}{$\begin{array}{l}\text { LOCAL } \\
\text { NO LEC DUMIMIES }\end{array}$} & \multicolumn{2}{|c|}{$\begin{array}{l}\text { ALL } \\
\text { W/LEC DUMMIES }\end{array}$} & \multicolumn{2}{|c|}{$\begin{array}{l}\text { LOCAL } \\
\text { W/LEC DUMMIISS }\end{array}$} \\
\hline & EST & $\underline{S . E R R} \mathrm{~T}$ & EST & $\underline{S . E R R} \mathrm{~T}$ & EST & S.ERR I & EST & $S . E R R$ \\
\hline GAMMA ON FIBER & 0.07 & $0.04^{* *}$ & 0.11 & $0.04^{* *}$ & 0.10 & 0.05 & 0.11 & 0.05 \\
\hline POLITICAL VARIABLES & & & & & & & & \\
\hline COMMISSION NOT ELECT & 0.35 & $0.09^{* *}$ & 0.48 & $0.10^{* *}$ & 0.41 & $0.09 * *$ & 0.55 & $0.10^{* *}$ \\
\hline DEM COMM MAJORITY & 0.28 & $0.10^{* *}$ & 0.45 & $0.11^{* *}$ & 0.33 & $0.10 * *$ & 0.50 & $0.11^{* *}$ \\
\hline NOT EL \& DEM COMM MAJ & -0.32 & $0.10^{* *}$ & -0.46 & $0.11 * *$ & -0.38 & $0.10 * *$ & -0.51 & $0.11 * *$ \\
\hline STATE VOTE DUKAKIS & -2.16 & $0.52 * *$ & -2.20 & $0.56 * *$ & -2.10 & $0.60^{* *}$ & -2.08 & $0.65^{* *}$ \\
\hline DEMOCRATIC GOVERNOR & -0.06 & 0.07 & -0.07 & 0.08 & -0.06 & 0.07 & -0.08 & 0.08 \\
\hline ALL LEG DEM & 0.09 & 0.07 & 0.12 & $0.07^{*}$ & 0.09 & 0.07 & 0.13 & $0.07^{*}$ \\
\hline ALL LEG REP & -0.09 & 0.09 & -0.10 & 0.10 & -0.10 & 0.09 & -0.11 & 0.10 \\
\hline ALIGN GOV, REG, LEG & -0.11 & 0.07 & -0.07 & 0.08 & -0.12 & $0.07 *$ & -0.10 & 0.08 \\
\hline ALL REG, GOV & 0.02 & 0.07 & 0.02 & 0.07 & 0.04 & 0.07 & 0.04 & 0.07 \\
\hline $\begin{array}{l}\text { STATE DEMOGRAPHICS } \\
\text { STATE GNP GROWTH }\end{array}$ & & & & & & & & \\
\hline $\begin{array}{l}\text { GNP GROWTH } \\
\text { ATE/LOC PCAPINC }\end{array}$ & $\begin{array}{r}0.00 \\
-2.23\end{array}$ & $\begin{array}{l}0.01 \\
0.45^{* *}\end{array}$ & $\begin{array}{r}0.00 \\
-3.27\end{array}$ & $\begin{array}{l}0.01 \\
0.49 * *\end{array}$ & $\begin{array}{r}0.00 \\
-1.99\end{array}$ & $\begin{array}{l}0.01 \\
0.52 * *\end{array}$ & $\begin{array}{r}0.00 \\
-2.43\end{array}$ & $\begin{array}{l}0.01 \\
0.56 * *\end{array}$ \\
\hline FRAC ST GNP IN FIRE & 10.39 & $2.73^{* *}$ & 13.63 & $2.95 * *$ & 8.78 & $2.82 * *$ & 11.72 & $3.06^{* *}$ \\
\hline LOCAL DEMOGRAPHICS & & & & & & & & \\
\hline FRAC & 0.92 & $0.24 * *$ & 1.11 & $0.26^{* *}$ & 0.94 & $0.25 * *$ & 1.09 & $0.27^{* *}$ \\
\hline FRAC & 1.69 & $0.29 * *$ & 1.91 & $0.31 * *$ & 1.53 & $0.29^{* *}$ & 1.72 & $0.31 * *$ \\
\hline PULATION & 0.71 & $0.05^{* *}$ & 0.67 & $0.05 * *$ & 0.70 & $0.06^{* *}$ & 0.66 & $0.07^{* *}$ \\
\hline APITA INCOME & 0.26 & 0.29 & -0.20 & 0.31 & 0.04 & 0.33 & -0.39 & 0.35 \\
\hline PULATION DENS & -0.09 & $0.03^{* *}$ & -0.06 & $0.03^{*}$ & -0.10 & $0.04 * *$ & -0.03 & 0.04 \\
\hline (FRAC ST EMP $<10 \%$ ) & 0.21 & $0.07^{* *}$ & 0.16 & $0.08^{* *}$ & 0.19 & $0.08 * *$ & 0.16 & $0.08 *$ \\
\hline UMM & -0.07 & 0.07 & -0.06 & 0.08 & -0.07 & 0.07 & -0.04 & 0.08 \\
\hline 90 & -0.13 & $0.08 *$ & -0.08 & 0.08 & -0.13 & $0.08 *$ & -0.06 & 0.09 \\
\hline 1 & -0.19 & $0.09 * *$ & -0.13 & 0.09 & -0.19 & $0.09^{* *}$ & -0.10 & 0.10 \\
\hline DUMMY 92 & -0.21 & $0.09 * *$ & -0.11 & 0.10 & -0.24 & $0.10^{* *}$ & -0.11 & 0.11 \\
\hline CITY OF QUARTER MIL & 0.46 & $0.07^{* *}$ & 0.57 & $0.07^{* *}$ & 0.49 & $0.07^{* *}$ & 0.56 & $0.07 * *$ \\
\hline ITY OF HALF MIL & 0.23 & $0.07^{* *}$ & 0.34 & $0.07^{* *}$ & 0.32 & $0.08 * *$ & 0.39 & $0.08 * *$ \\
\hline FASTGROW & -0.11 & 0.07 & -0.26 & $0.08 * *$ & -0.16 & $0.08 * *$ & -0.30 & $0.08^{* *}$ \\
\hline CONS & 3.82 & 2.57 & 6.55 & $2.78 * *$ & 5.89 & $2.93 * *$ & 8.04 & $3.19^{* *}$ \\
\hline GTE & & & & & 0.01 & 0.12 & 0.15 & 0.13 \\
\hline INDEPENDENT & & & & & 0.23 & $0.13 *$ & 0.40 & $0.14 * *$ \\
\hline AMERITECH & & & & & -0.24 & 0.18 & 0.08 & 0.19 \\
\hline BELL ATLANTIC & & & & & 0.06 & 0.15 & 0.31 & $0.17^{*}$ \\
\hline BELL SOUTH & & & & & 0.02 & 0.16 & 0.40 & $0.17^{* *}$ \\
\hline NYNEX & & & & & 0.21 & 0.15 & 0.50 & $0.16^{* *}$ \\
\hline PACIFIC BELL & & & & & 0.05 & 0.20 & 0.50 & $0.22 * *$ \\
\hline SOUTHWESTERN BELL & & & & & 0.09 & 0.16 & 0.51 & $0.18^{* *}$ \\
\hline USWEST & & & & & 0.02 & 0.16 & 0.39 & $0.17^{* *}$ \\
\hline
\end{tabular}


FULL SAMPLE, 458 OBSERVATIONS, 1988-1992

FIBER ONLY

THREE STAGE LEAST SQUARES

COST EQUATION

\begin{tabular}{|c|c|c|c|c|c|c|c|c|}
\hline \multirow{2}{*}{$\begin{array}{l}\text { TYPE OF REVENUE } \\
\text { SPECIFICATION }\end{array}$} & \multicolumn{2}{|c|}{$\begin{array}{l}\text { ALL } \\
\text { NO LEC DUMMIISS }\end{array}$} & \multicolumn{2}{|c|}{$\begin{array}{l}\text { LOCAL } \\
\text { NO LEC DUMIMIES }\end{array}$} & \multicolumn{2}{|c|}{$\begin{array}{l}\text { ALL } \\
\text { W/LEC DUMMIIES }\end{array}$} & \multicolumn{2}{|c|}{$\begin{array}{l}\text { LOCAL } \\
\text { W/LEC DUMMIES }\end{array}$} \\
\hline & $\underline{\text { EST }}$ & $\underline{S . E R R} \mathrm{I}$ & EST & S.ERR I & EST & $\underline{S . E R R} \mathrm{~T}$ & $\underline{\text { EST }}$ & $\underline{S . E R R}$ \\
\hline CONSTANT, COST EQ & -1.96 & 2.16 & -1.56 & 2.17 & -1.52 & 2.16 & -1.46 & 2.22 \\
\hline LOG CONSTRUCT WAGES & 1.04 & $0.34^{* *}$ & 0.93 & $0.35 * *$ & 1.01 & $0.34 * *$ & 0.93 & $0.35 * *$ \\
\hline LOG CONSTRUCT EMPLOY & 0.24 & 0.20 & 0.25 & 0.20 & 0.24 & 0.20 & 0.22 & 0.20 \\
\hline CONSTRUCTION GROWTH & 0.01 & 0.00 & 0.01 & $0.00 *$ & 0.01 & $0.00 *$ & 0.01 & $0.00 *$ \\
\hline LOG POPULATION & -1.80 & $0.35^{* *}$ & -1.87 & $0.35^{* *}$ & -1.81 & $0.35 * *$ & -1.87 & $0.36^{* *}$ \\
\hline LOG POPULATION SQ & 0.23 & $0.02 * *$ & 0.23 & $0.02^{* *}$ & 0.23 & $0.02 * *$ & 0.23 & $0.03^{* *}$ \\
\hline LOG LAND AREA & 1.16 & $0.42^{* *}$ & 1.00 & $0.43^{* *}$ & 1.14 & $0.42 * *$ & 1.01 & $0.43^{* *}$ \\
\hline LOG LAND AREA SQ & 0.01 & 0.03 & 0.01 & 0.03 & 0.01 & 0.03 & 0.01 & 0.03 \\
\hline LOG LAND \& LOG POP & -0.19 & $0.04 * *$ & -0.17 & $0.04^{* *}$ & -0.18 & $0.04^{* *}$ & -0.16 & $0.04 * *$ \\
\hline GTE & 0.31 & 0.21 & 0.46 & $0.21 * *$ & 0.31 & 0.21 & 0.48 & $0.21^{* *}$ \\
\hline INDEPENDENT & 0.75 & $0.21 * *$ & 0.87 & $0.21 * *$ & 0.80 & $0.21^{* *}$ & 0.99 & $0.22 * *$ \\
\hline AMERITECH & -0.09 & 0.26 & 0.37 & 0.27 & -0.11 & 0.26 & 0.37 & 0.27 \\
\hline BELL ATLANTIC & -0.48 & $0.25 *$ & -0.15 & 0.26 & -0.46 & $0.25 *$ & -0.09 & 0.26 \\
\hline BELL SOUTH & 0.13 & 0.26 & 0.56 & $0.27^{* *}$ & 0.14 & 0.26 & 0.65 & $0.27^{* *}$ \\
\hline NYNEX & -0.55 & $0.24^{* *}$ & -0.28 & 0.25 & -0.50 & $0.24^{* *}$ & -0.15 & 0.25 \\
\hline PACIFIC BELL & -0.77 & $0.35 * *$ & -0.49 & 0.35 & -0.76 & $0.35 * *$ & -0.38 & 0.36 \\
\hline SOUTHWESTERN BELL & -0.11 & 0.27 & 0.27 & 0.27 & -0.09 & 0.27 & 0.38 & 0.28 \\
\hline USWEST & -0.33 & 0.24 & 0.08 & 0.25 & -0.31 & 0.24 & 0.17 & 0.25 \\
\hline LOG (I+FIBER) IN 1986 & -0.04 & $0.02 *$ & -0.04 & $0.02 * *$ & -0.04 & $0.02 * *$ & -0.05 & $0.02 * *$ \\
\hline DUMMY 89 & -0.60 & $0.12 * *$ & -0.59 & $0.12 * *$ & -0.60 & $0.12 * *$ & -0.59 & $0.12^{* *}$ \\
\hline DUMMY 90 & -1.04 & $0.12 * *$ & -1.00 & $0.12^{* *}$ & -1.04 & $0.12^{* *}$ & -0.99 & $0.12 * *$ \\
\hline DUMMY 91 & -1.29 & $0.12 * *$ & -1.22 & $0.13^{* *}$ & -1.29 & $0.12^{* *}$ & -1.22 & $0.13^{* *}$ \\
\hline DUMMY 92 & -1.69 & $0.12 * *$ & -1.58 & $0.12^{* *}$ & -1.69 & $0.12 * *$ & -1.58 & $0.12 * *$ \\
\hline
\end{tabular}


PARTIAL SAMPLE, 309 OBSERVATIONS, 1988-1992

FIBER, ISDN

THREE STAGE LEAST SOUARES

REVENUE EQUATION

\begin{tabular}{|c|c|c|c|c|c|c|c|c|}
\hline \multirow[t]{2}{*}{$\begin{array}{l}\text { TYPE OF REVENUE } \\
\text { SPECIFICATION }\end{array}$} & \multicolumn{2}{|c|}{$\begin{array}{l}\text { ALL } \\
\text { NO LEC DUMMIES }\end{array}$} & \multicolumn{2}{|c|}{$\begin{array}{l}\text { LOCAL } \\
\text { NO LEC DUMMIES }\end{array}$} & \multicolumn{2}{|c|}{$\begin{array}{l}\text { ALL } \\
\text { W/ LEC DUMMIES }\end{array}$} & \multicolumn{2}{|c|}{$\begin{array}{l}\text { LOCAL } \\
\text { W/LEC DUMMIIES }\end{array}$} \\
\hline & $\underline{\text { EST }}$ & $\underline{S . E R R} \mathrm{~T}$ & EST & S.ERR T & EST & $\underline{S . E R R} \mathrm{I}$ & EST & $\underline{S . E R R} \underline{\mathrm{T}}$ \\
\hline GAMMA ON FIBER & 0.28 & 0.19 & 0.11 & $0.04^{* *}$ & 0.42 & $0.06^{* *}$ & 0.19 & $0.05^{* *}$ \\
\hline GAMMA ON ISDN & 0.00 & 2.45 & 0.03 & 0.03 & 0.44 & $0.06^{* *}$ & 0.19 & $0.05 * *$ \\
\hline POLITICAL VARIABLES & & & & & & & & \\
\hline COMMISSION NOT ELECT & 0.41 & 0.30 & 0.47 & $0.11 * *$ & 0.30 & $0.09^{* *}$ & 0.39 & $0.10^{* *}$ \\
\hline DEM COMM MAJORITY & 0.48 & 0.33 & 0.56 & $0.12 * *$ & 0.37 & $0.10^{* *}$ & 0.50 & $0.10^{* *}$ \\
\hline NOT EL \& DEM COMM MAJ & -0.38 & 0.34 & -0.43 & $0.13^{* *}$ & -0.34 & $0.10^{* *}$ & -0.39 & $0.11 * *$ \\
\hline STATE VOTE DUKAKIS & -2.11 & 1.53 & -2.17 & $0.58^{* *}$ & -1.68 & $0.57 * *$ & -1.63 & $0.60^{* *}$ \\
\hline DEMOCRATIC GOVERNOR & -0.04 & 0.20 & -0.03 & 0.08 & -0.01 & 0.06 & -0.02 & 0.06 \\
\hline ALL LEG DEM & -0.01 & 0.21 & 0.06 & 0.08 & 0.00 & 0.07 & 0.04 & 0.07 \\
\hline ALL LEG REP & -0.10 & 0.26 & -0.10 & 0.10 & -0.08 & 0.08 & -0.09 & 0.08 \\
\hline ALIGN GOV, REG, LEG & -0.12 & 0.21 & -0.05 & 0.08 & -0.11 & $0.06^{*}$ & -0.07 & 0.07 \\
\hline ALL REG, GOV & 0.00 & 0.21 & -0.08 & 0.08 & 0.04 & 0.06 & 0.01 & 0.07 \\
\hline STATE DEMOGRAPHICS & & & & & & & & \\
\hline STATE GNP GROWTH & -0.01 & 0.04 & -0.01 & 0.01 & 0.01 & 0.01 & 0.01 & 0.01 \\
\hline LOG STATE/LOC PCAPINC & -2.78 & $1.56^{*}$ & -3.67 & $0.59^{* *}$ & -1.55 & $0.50^{* *}$ & -2.37 & $0.54^{* *}$ \\
\hline FRAC ST GNP IN FIRE & 3.13 & 9.21 & 5.01 & 3.50 & -0.18 & 2.90 & 4.41 & 3.09 \\
\hline LOCAL DEMOGRAPHICS & & & & & & & & \\
\hline FRAC URBANIZED & 1.27 & $0.77^{*}$ & 1.08 & $0.30^{* *}$ & 1.25 & $0.28 * *$ & 1.35 & $0.30 * *$ \\
\hline FRAC RURAL & 1.40 & 0.89 & 1.28 & $0.34^{* *}$ & 1.34 & $0.31 * *$ & 1.51 & $0.33 * *$ \\
\hline LOG POPULATION & 0.85 & $0.16^{* *}$ & 0.83 & $0.06 * *$ & 0.72 & $0.07 * *$ & 0.72 & $0.07^{* *}$ \\
\hline LOG PERCAPITA INCOME & 0.21 & 0.87 & -0.02 & 0.33 & 0.19 & 0.34 & -0.19 & 0.36 \\
\hline LOG POPULATION DENS & -0.09 & 0.10 & -0.06 & $0.04 *$ & -0.19 & $0.04^{* *}$ & -0.14 & $0.04^{* *}$ \\
\hline SMALL (FRAC ST EMP $<10 \%$ ) & 0.60 & $0.27^{* *}$ & 0.56 & $0.10 * *$ & 0.43 & $0.09 * *$ & 0.47 & $0.10^{* *}$ \\
\hline DUMMY 90 & -0.05 & 0.18 & -0.05 & 0.07 & -0.27 & $0.07^{* *}$ & -0.22 & $0.08^{* *}$ \\
\hline DUMMY 91 & -0.12 & 0.20 & -0.14 & $0.08 *$ & -0.46 & $0.10^{* *}$ & -0.40 & $0.10^{* *}$ \\
\hline DUMMY 92 & -0.15 & 0.25 & -0.12 & 0.10 & -0.66 & $0.13^{* *}$ & -0.55 & $0.14^{* *}$ \\
\hline CITY OF QUARTER MIL & 0.18 & 0.25 & 0.20 & $0.09 * *$ & 0.10 & 0.09 & 0.09 & 0.09 \\
\hline CITY OF HALF MIL & -0.02 & 0.21 & 0.04 & 0.08 & 0.04 & 0.07 & 0.05 & 0.07 \\
\hline FASTGROW & -0.07 & 0.21 & -0.15 & $0.08 *$ & -0.12 & 0.08 & -0.23 & $0.08^{* *}$ \\
\hline CONSTANT, REV EQ & 3.63 & 7.87 & 4.53 & 3.03 & 4.33 & 3.15 & 5.77 & $3.34 *$ \\
\hline GTE & & & & & 0.12 & 0.11 & 0.29 & $0.12 * *$ \\
\hline INDEPENDENT & & & & & 0.84 & $0.23^{* *}$ & 1.06 & $0.24 * *$ \\
\hline AMERITECH & & & & & -0.61 & $0.22 * *$ & -0.19 & 0.23 \\
\hline BELL ATLANTIC & & & & & -0.67 & $0.24 * *$ & -0.41 & $0.25 *$ \\
\hline BELL SOUTH & & & & & -0.52 & $0.19^{* *}$ & -0.12 & 0.20 \\
\hline NYNEX & & & & & -0.12 & 0.18 & 0.19 & 0.19 \\
\hline PACIFIC BELL & & & & & -0.53 & $0.20 * *$ & -0.13 & 0.22 \\
\hline SOUTHWESTERN BELL & & & & & -0.34 & $0.18 *$ & 0.08 & 0.19 \\
\hline USWEST & & & & & -0.66 & $0.21 * *$ & -0.30 & 0.22 \\
\hline
\end{tabular}


PARTIAL SAMPLE, 309 OBSERVATIONS, 1988-1992

FIBER, ISDN

THREE STAGE LEAST SOUARES

COST EQUATION, FIBER

\begin{tabular}{|c|c|c|c|c|c|c|c|c|}
\hline \multirow[t]{2}{*}{$\begin{array}{l}\text { TYPE OF REVENUE } \\
\text { SPECIFICATION }\end{array}$} & \multicolumn{2}{|c|}{$\begin{array}{l}\text { ALL } \\
\text { NO LEC DUMMIIES }\end{array}$} & \multicolumn{2}{|c|}{$\begin{array}{l}\text { LOCAL } \\
\text { NO LEC DUMMIES }\end{array}$} & \multicolumn{2}{|c|}{\begin{tabular}{|l} 
ALL \\
W/ LEC DUMMIES
\end{tabular}} & \multicolumn{2}{|c|}{$\begin{array}{l}\text { LOCAL } \\
\text { W/LEC DUMMIISS }\end{array}$} \\
\hline & EST & $\underline{S E R R} \underline{\mathrm{T}}$ & $\underline{\text { EST }}$ & $\underline{S . E R R} \underline{\mathrm{T}}$ & $\underline{\text { EST }}$ & $\underline{S . E R R} \mathrm{I}$ & EST & S.ERR I \\
\hline CONSTANT, COST EQ & -0.90 & 3.43 & -1.71 & 2.08 & 0.22 & 2.02 & -1.06 & 2.05 \\
\hline LOG CONSTRUCT WAGES & 0.10 & 0.59 & -0.05 & 0.36 & 0.13 & 0.35 & -0.01 & 0.36 \\
\hline LOG CONSTRUCT EMPLOY & 0.09 & 0.34 & 0.03 & 0.20 & 0.09 & 0.20 & 0.03 & 0.20 \\
\hline CONSTRL & 0.00 & 0.01 & 0.00 & 0.01 & 0.00 & 0.00 & 0.00 & 0.01 \\
\hline LOG POPULATION & -1.17 & $0.60 *$ & -1.19 & $0.36 * *$ & -1.26 & $0.36^{* *}$ & -1.22 & $0.36^{*}$ \\
\hline LOG POPULATION SQ & 0.24 & $0.04^{* *}$ & 0.24 & $0.02 * *$ & 0.24 & $0.02 * *$ & 0.23 & $0.02 *$ \\
\hline LOG LAND AREA & 1.25 & $0.65^{*}$ & 1.13 & $0.39 * *$ & 1.12 & $0.39 * *$ & 1.09 & $0.39 *$ \\
\hline \multirow[t]{2}{*}{ LOG LAND AREA SQ } & 0.04 & 0.05 & 0.03 & 0.03 & 0.04 & 0.03 & 0.03 & 0.03 \\
\hline & -0.26 & $0.07 * *$ & -0.23 & $0.04^{* *}$ & -0.24 & $0.04^{* *}$ & -0.22 & $0.04 * *$ \\
\hline GTE & 0.35 & 0.31 & 0.48 & $0.19 * *$ & 0.35 & $.19^{*}$ & 0.54 & $.19 * *$ \\
\hline DEPEN & 1.16 & $0.59 *$ & 1.25 & $0.36^{* *}$ & 1.19 & $0.36^{* *}$ & 1.43 & $0.36 *$ \\
\hline MERITECH & -0.37 & 0.40 & 0.10 & 0.24 & -0.34 & 0.24 & 0.12 & 0.24 \\
\hline BELL AT & -0.83 & $0.38^{* *}$ & -0.45 & $0.23 *$ & -0.80 & $0.23 * *$ & -0.42 & $0.23 *$ \\
\hline ELL SOUTH & -0.47 & & -0.01 & 0.25 & -0.45 & $.25 *$ & 0.00 & .25 \\
\hline YNEX & -0.70 & $0.36^{* *}$ & -0.41 & $0.22 *$ & -0.68 & $21 * *$ & -0.32 & .22 \\
\hline PACIFIC BELL & -0.84 & $0.51 *$ & -0.48 & 0.31 & -0.86 & $.31 * *$ & -0.47 & 0.31 \\
\hline SOUTHWESTERN BELL & -0.41 & 0.41 & -0.04 & 0.25 & -0.42 & $0.24 *$ & 0.01 & 0.25 \\
\hline USWEST & -0.80 & $0.37^{* *}$ & -0.39 & $0.22 *$ & -0.80 & $0.22 * *$ & -0.37 & $0.23 *$ \\
\hline LOG $(1+$ FIBER $)$ & 0.03 & 0.04 & 0.02 & 0.02 & 0.02 & 0.02 & 0.03 & 0.02 \\
\hline DUMMY 90 & -0.39 & $0.16^{* *}$ & -0.36 & $0.10^{* *}$ & -0.39 & $0.10^{* *}$ & -0.36 & $0.10^{* *}$ \\
\hline DUMMY 91 & -0.74 & $0.17^{* *}$ & -0.69 & $0.10^{* *}$ & -0.74 & $0.10 * *$ & -0.69 & $0.10^{* *}$ \\
\hline DUMMY 92 & -1.05 & $0.17^{* *}$ & -0.97 & $0.10 * *$ & -1.05 & $0.10^{* *}$ & -0.97 & $0.10 * *$ \\
\hline
\end{tabular}


PARTIAL SAMPLE, 309 OBSERVATIONS, 1988-1992

FIBER, ISDN

THREE STAGE LEAST SQUARES

COST EQUATION, ISDN

\begin{tabular}{|c|c|c|c|c|c|c|c|c|}
\hline \multirow[t]{2}{*}{$\begin{array}{l}\text { TYPE OF REVENUE } \\
\text { SPECIFICATION }\end{array}$} & \multicolumn{2}{|c|}{$\begin{array}{l}\text { ALL } \\
\text { NO LEC DUMMIES }\end{array}$} & \multicolumn{2}{|c|}{$\begin{array}{l}\text { LOCAL } \\
\text { NO LEC DUMMIES }\end{array}$} & \multicolumn{2}{|c|}{$\begin{array}{l}\text { ALL } \\
\text { W/ LEC DUMMIES }\end{array}$} & \multicolumn{2}{|c|}{$\begin{array}{l}\text { LOCAL } \\
\text { W/ LEC DUMMIIES }\end{array}$} \\
\hline & EST & S.ERR I & EST & $\underline{S . E R R} \underline{\mathrm{T}}$ & $\underline{\mathrm{EST}}$ & $\underline{S . E R R} \underline{\mathrm{T}}$ & $\underline{\text { EST }}$ & $\underline{S E R R} \mathrm{I}$ \\
\hline CONSTANT, COST EQ & -4.54 & 16.93 & 0.62 & 4.37 & 8.58 & $3.87^{* *}$ & 6.37 & 3.98 \\
\hline LOG CONSTRUCT WAGES & -0.63 & 0.59 & -0.72 & 0.75 & -0.24 & 0.72 & -0.35 & 0.73 \\
\hline LOG CONSTRUCT EMPLOY & -0.24 & 0.34 & -0.30 & 0.43 & -0.23 & 0.39 & -0.30 & 0.40 \\
\hline CONSTRUCTION GROWTH & 0.01 & 0.01 & 0.01 & 0.01 & 0.00 & 0.01 & 0.01 & 0.01 \\
\hline LOG POPULATION & 1.71 & $0.60 * *$ & 1.53 & $0.76^{* *}$ & 0.88 & 0.69 & 1.09 & 0.70 \\
\hline LOG POPULATION SQ & -0.07 & $0.04 *$ & -0.09 & $0.05 *$ & -0.14 & $0.05 * *$ & -0.14 & $0.05 * *$ \\
\hline LOG LAND AREA & 1.44 & $0.65^{* *}$ & 0.98 & 0.82 & 0.10 & 0.75 & 0.15 & 0.77 \\
\hline \multirow[t]{2}{*}{ LOG LAND AREA SQ } & -0.06 & 0.05 & -0.06 & 0.06 & -0.04 & 0.06 & -0.05 & 0.06 \\
\hline & -0.02 & 0.07 & 0.04 & 0.09 & 0.16 & $0.08^{* *}$ & 0.15 & $0.08 *$ \\
\hline GTE & -0.42 & 0.31 & -0.40 & 0.39 & -0.37 & 0.39 & -0.19 & 0.40 \\
\hline INDEPENDENT & -0.17 & 0.59 & -0.38 & 0.75 & 0.10 & 0.74 & 0.34 & 0.76 \\
\hline AMERITECH & -2.56 & $0.40^{* *}$ & -2.04 & $0.50^{* *}$ & -2.26 & $0.49^{* *}$ & -1.82 & $0.50 * *$ \\
\hline BELL ATLANTIC & -3.49 & $0.38 * *$ & -3.04 & $0.48^{* *}$ & -3.11 & $0.48^{* *}$ & -2.77 & $0.48^{* *}$ \\
\hline BELL SOUTH & -1.92 & $0.41 * *$ & -1.42 & $0.52 * *$ & -1.73 & $0.51 * *$ & -1.26 & $0.52 * *$ \\
\hline NYNEX & -1.46 & $0.36^{* *}$ & -1.30 & $0.45^{* *}$ & -1.23 & $0.45^{* *}$ & -0.88 & 0.46 * \\
\hline PACIFIC BELL & -1.87 & $0.51^{* *}$ & -1.59 & $0.65 * *$ & -2.06 & $0.64^{* *}$ & -1.65 & $0.65 * *$ \\
\hline SOUTHWESTERN BELL & -1.84 & $0.41 * *$ & -1.59 & $0.52 * *$ & -1.91 & $0.51 * *$ & -1.45 & $0.52 * *$ \\
\hline USWEST & -2.82 & $0.37 * *$ & -2.44 & $0.47^{* *}$ & -2.82 & $0.46^{* *}$ & -2.38 & $0.47^{* *}$ \\
\hline LOG (1+FIBER) IN 1986 & -0.16 & $0.04^{* *}$ & -0.18 & $0.05^{* *}$ & -0.17 & $0.05 * *$ & -0.17 & $0.05 * *$ \\
\hline DUMMY 90 & -0.94 & $0.16 * *$ & -0.91 & $0.21 * *$ & -0.94 & $0.21 * *$ & -0.91 & $0.21 * *$ \\
\hline DUMMY 91 & -1.56 & $0.17 * *$ & -1.51 & $0.22 * *$ & -1.58 & $0.21 * *$ & -1.52 & $0.22 * *$ \\
\hline DUMMY 92 & -2.03 & $0.17 * *$ & -1.93 & $0.22 * *$ & -2.00 & $0.21 * *$ & -1.93 & $0.22 * *$ \\
\hline
\end{tabular}

